\title{
Tissue heme oxygenase- 1 exerts anti-inflammatory effects on LPS-induced pulmonary inflammation
}

\author{
FM Konrad ${ }^{1}$, U Knausberg ${ }^{1}$, R Höne $^{1}$, K-C Ngamsri $^{1}$ and J Reutershan ${ }^{1}$
}

Heme oxygenase-1 (HO-1) has been shown to display anti-inflammatory properties in models of acute pulmonary inflammation. For the first time, we investigated the role of leukocytic HO-1 using a model of HO- ${ }^{\text {flox/flox }}$ mice lacking leukocytic HO-1 that were subjected to lipopolysaccharide (LPS)-induced acute pulmonary inflammation. Immunohistology and flow cytometry demonstrated that activation of HO-1 using hemin decreased migration of polymorphonuclear leukocytes (PMNs) to the lung interstitium and bronchoalveolar lavage (BAL) in the wild-type and, surprisingly, also in HO-1 flox/flox mice, emphasizing the anti-inflammatory potential of nonmyeloid HO-1. Nevertheless, hemin reduced the CXCL1, CXCL2/3, tumor necrosis factor- $\alpha$ (TNF $\alpha$ ), and interleukin 6 (IL6) levels in both animal strains. Microvascular permeability was attenuated by hemin in wild-type and $\mathrm{HO}-1^{\text {flox/flox }}$ mice, indicating a crucial role of non-myeloid HO-1 in endothelial integrity. The determination of the activity of HO-1 in mouse lungs revealed no compensatory increase in the $\mathrm{HO}-1^{\text {flox/flox }}$ mice. Topical administration of hemin via inhalation reduced the dose required to attenuate PMN migration and microvascular permeability by a factor of 40 , emphasizing its clinical potential. In addition, HO-1 stimulation was protective against pulmonary inflammation when initiated after the inflammatory stimulus. In conclusion, nonmyeloid HO-1 is crucial for the anti-inflammatory effect of this enzyme on PMN migration to different compartments of the lung and on microvascular permeability.

\section{INTRODUCTION}

In humans, acute lung injury (ALI) and its more severe form, acute respiratory distress syndrome, remain frightening complications in intensive care units and affect $7-10 \%$ of admitted patients, resulting in a mortality rate of $40 \%{ }^{1}$

The two major characteristics of ALI are an increase in microvascular permeability due to the deterioration of endothelial integrity and an excessive infiltration of polymorphonuclear leukocytes (PMNs), leading to tissue destruction. ${ }^{2}$ Experimental studies have shown that decreasing the migrated PMN count leads to reduced tissue destruction, decreased mortality, and therefore increased survival. ${ }^{3}$ In cases of pulmonary inflammation, PMNs are released from the bone marrow, circulate in the vascular system, and migrate via the vascular endothelium to the site of inflammation. ${ }^{4}$ This transendothelial migration to the lung interstitium is followed by a transepithelial migration of PMNs to the alveolar system. These migration steps underlie different regulatory mechanisms. ${ }^{4}$

Heme oxygenase $(\mathrm{HO})$ is an enzyme that is expressed ubiquitously in nearly every tissue of the body. $\mathrm{HO}$ was initially discovered in 1968 as the rate-limiting enzyme in the enzymatic conversion of heme to bile pigments. ${ }^{5}$ Subsequently, HO was identified as a stress response protein and as a critical mediator of cellular homeostasis. Therefore, $\mathrm{HO}$ has been the focus of research interest in many fields such as pulmonology, ${ }^{6}$ cardiology, ${ }^{7}$ and transplant immunology. ${ }^{8}$

$\mathrm{HO}$ is expressed as three isoenzymes. HO- 1 and HO-2 differ in primary amino acid sequence and are products of two different genes; it remains unclear whether HO-3 is a pseudogene. ${ }^{9} \mathrm{HO}-1$ is of major interest, primarily because of its pharmacological accessibility. Heme catalyzation through HO-1 releases carbon monoxide, biliverdin that is converted to bilirubin, and iron that is bound to ferritin. ${ }^{10}$

${ }^{1}$ Department of Anesthesiology and Intensive Care Medicine, University Hospital of Tübingen, Tübingen, Germany. Correspondence: J Reutershan (joerg.reutershan@uni-tuebingen.de) 
The cytoprotective effects of HO-1 are mainly attributed to its enzymatic reaction products, and studies have focused on developing the therapeutic delivery of these substances ${ }^{11,12}$ or the induction of $\mathrm{HO}-1 .{ }^{13,14}$

HO-1 plays a pivotal role in the defense against oxidative and inflammatory processes in the lung. ${ }^{15}$ Activating HO-1 has been shown to attenuate hyperoxic lung injury in rats, ${ }^{16}$ cecal ligation and puncture-induced ALI in mice, ${ }^{17}$ trauma-hemorrhage-induced lung injury in rats, ${ }^{18}$ and ventilator-induced ALI in rabbits. ${ }^{19}$

HO-1 is expressed in lung endothelial ${ }^{20-22}$ and epithelial cells, ${ }^{23,24}$ monocytes, ${ }^{25}$ and neutrophils. ${ }^{26}$ At present, it is unclear whether HO-1 in nonmyeloid cells (endothelial or epithelial cells) or myeloid cells (PMNs or monocytes) is predominantly responsible for the anti-inflammatory effects of $\mathrm{HO}-1$ on ALI. Therefore, we investigated the role of nonmyeloid and myeloid HO-1 in a murine model of lipopolysaccharide (LPS)-induced lung inflammation. We used HO- $1^{\text {flox/flox }}$ mice that lack HO-1 only in leukocytic cells and compared these mice with wild-type controls. In addition, we investigated the topical use of the HO-1 activator hemin and its effects when administered after an inflammatory stimulus (after treatment).

\section{RESULTS}

\section{Blood counts}

The PMN counts and the differential blood counts excluded any generic differences between the $\mathrm{HO}-1^{\text {flox/flox }}$ and wild-type mice (Table 1), indicating that the immune cell counts in the migration experiments were comparable between the two strains and were not affected by compensatory alterations in the genetically modified mice.

HO-1 expression in the wild-type and HO-1 ${ }^{\text {flox/flox }}$ animals We compared the leukocytic blood cells of the wild-type and $\mathrm{HO}-1^{\text {flox/flox }}$ mice to verify the genotyping results at the protein level. Immunofluorescence staining for HO-1 expression was performed using a specific antibody such that the enzyme appeared green. Leukocytes were also labeled with specific antibodies depending on the cell types of interest and emerge red. Representative images of monocytes (Supplementary Figure S1A online), PMNs (Supplementary Figure S1B), and lymphocytes (Supplementary Figure S1C) from the wild-type and $\mathrm{HO}-1^{\text {flox/flox }}$ mice demonstrate specific HO-1 staining in the wild-type animals but not in the $\mathrm{HO}-1^{\text {flox/flox }}$ mice.

Table 1 Differential cell counts of immune cells of the wildtype and HO-1 ${ }^{\text {flox/flox }}$ mice

\begin{tabular}{lccc}
\hline & Wild type $\left(\times \mathbf{1 0 ^ { 6 }}\right)$ & HO-1 $^{\text {floxflox }}\left(\times \mathbf{1 0 ^ { 6 }}\right)$ & $\boldsymbol{P}$-value \\
\hline Leukocytes & $19.1 \pm 0.5$ & $18.7 \pm 0.5$ & $\mathrm{NS}$ \\
Neutrophils & $1.8 \pm 0.7$ & $2.1 \pm 0.5$ & $\mathrm{NS}$ \\
Lymphocytes & $16.2 \pm 1.5$ & $15.7 \pm 1.0$ & $\mathrm{NS}$ \\
Monocytes & $0.8 \pm 0.0$ & $0.7 \pm 0.1$ & $\mathrm{NS}$ \\
\hline
\end{tabular}

$\mathrm{HO}-1$, heme oxygenase-1; NS, not significant.

Mean \pm s.d.; $n=4$.
Reverse transcriptase-PCR analyses of PMNs and mononuclear cells isolated from the bone marrow of the wild-type and $\mathrm{HO}-1^{\text {flox/flox }}$ mice confirmed these results (Supplementary Figure S1D), even after inflammatory simulation and induction of HO-1.

To compare the distribution of HO-1 in the lungs of the wildtype and HO- $1^{\text {flox/flox }}$ mice, immunofluorescence staining was performed (Figure 1). Before LPS inhalation, HO-1 expression was comparable between the two strains. Hemin did not alter HO-1 expression in the absence of an inflammatory stimulus (Supplementary Figure S2). After LPS inhalation, HO-1 was predominantly localized to the intraalveolar septa of both strains and, additionally, in alveolar macrophages of the wild-type mice. Activation of HO-1 further increased the expression of $\mathrm{HO}-1$ in alveolar macrophages of wild-type animals. The expression of HO- 1 in tissue was comparable between the two strains.

\section{HO-1 activation decreased PMN migration based on immunohistology}

Lung infiltration of PMNs was detected semiquantitatively via immunohistology after the activation/inhibition of HO-1 in the wild-type and $\mathrm{HO}-1^{\text {flox/flox }}$ mice. PMNs were labeled with a specific antibody such that they appeared brown. No difference was observed between the control groups of wild-type and HO- $1^{\text {flox/flox }}$ animals (Figure 2a,b). After LPS inhalation, the intraalveolar septa appeared thickened and PMN influx increased in both strains (Figure 2c,d). The stimulation of HO-1 decreased PMN migration and preserved the intra-

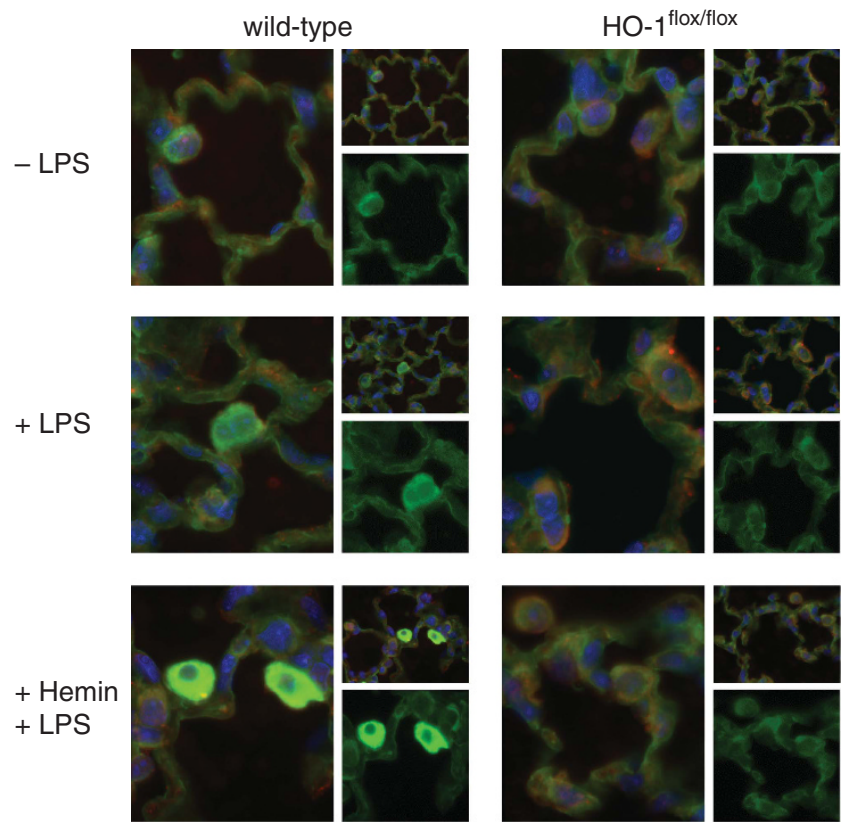

Figure 1 Immunofluorescence for heme oxygenase-1 (HO-1) expression in the lungs of the wild-type and $\mathrm{HO}-1^{\text {flox/flox }}$ mice. $\mathrm{HO}-1$ was labeled with a specific antibody (rat anti-mouse $\mathrm{HO}-1$ ) and appears green in the sections; nuclei appear blue; and the endothelium appears red. After lipopolysaccharide (LPS) administration, HO-1 was predominantly localized to the intraalveolar septa of both strains and in alveolar macrophages in the wild-type animals. A representative is shown $(n=4)$. 
a

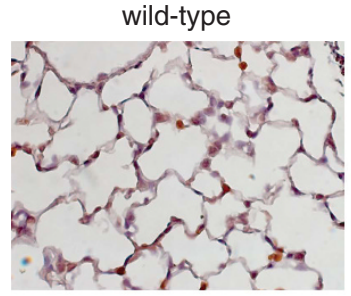

C

+ LPS

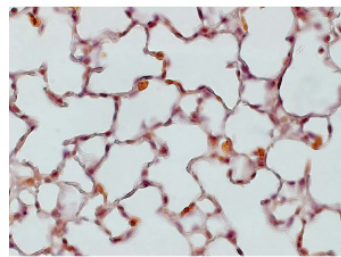

e

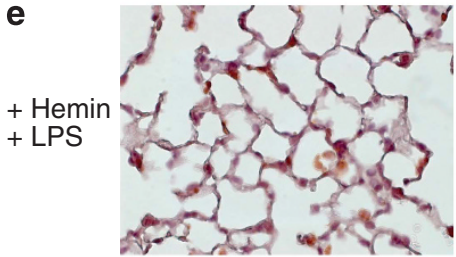

g

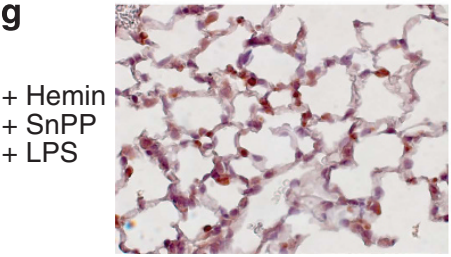

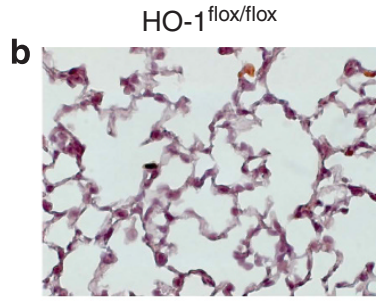
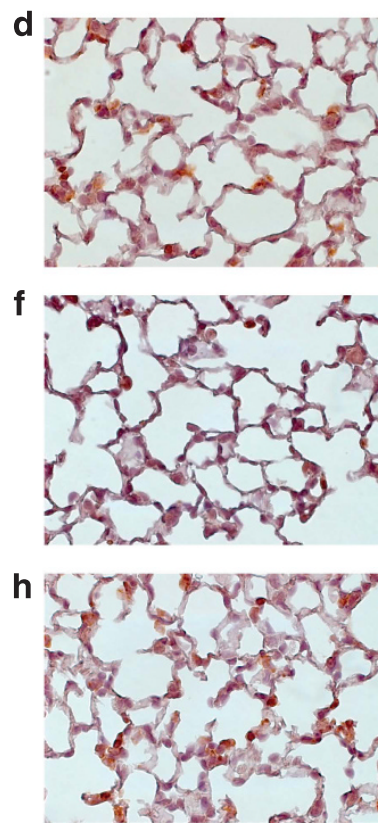

Figure 2 Immunohistochemistry on the wild-type and HO-1 $1^{\text {flox/flox }}$ mice. Neutrophils were stained with a specific neutrophil marker (rat anti-mouse neutrophils, clone 7/4) such that they appear brown in the histologic images (original magnification $\times 64$ ). Images of the

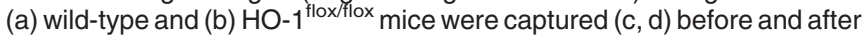
lipopolysaccharide (LPS) inhalation. Mice treated with $(e, f)$ hemin or $(g, h)$ hemin + SnPP and were subjected to LPS inhalation for $24 \mathrm{~h}$. The images are representative of four experiments. HO-1, heme oxygenase-1; SnPP, tin-protophorphyrin-IX.

alveolar architecture; surprisingly, no difference was observed between the wild-type and HO- $1^{\text {flox/flox }}$ mice (Figure 2e,f), indicating that nonmyeloid HO-1 is responsible for this antiinflammatory effect. The inhibition of HO- 1 further increased the PMN counts and the histological signs of tissue damage in both strains (Figure 2g,h).

\section{In vivo PMN migration assay in the wild-type and HO-1 ${ }^{\text {flox/flox }}$ mice}

To quantify PMN migration to different compartments of the lung (intravascular, interstitial, intraalveolar), PMNs were labeled with specific antibodies and were identified via flow cytometry. Representative fluorescence-activated cell sorting plots and the gating process are shown in Supplementary Figure S3C. No differences were observed between the control, HO-1-activated, and HO-1-inhibited groups of wild-type and HO- $1^{\text {flox/flox }}$ mice before LPS inhalation (Supplementary Figure S3A,B). In the intravascular compartment of the wild-type mice, LPS inhalation caused an increase in the number of migrated PMNs $\left(3.1 \pm 1.1 \times 10^{6}\right.$ vs. $1.3 \pm 0.9 \times 10^{6}$;

$P<0.05$; Figure 3a). The activation of HO- 1 abolished the LPSinduced rise of PMN counts $\left(1.9 \pm 1 \times 10^{6} ; P<0.05\right)$, whereas inhibition of HO-1 further enhanced PMNs attached to the endothelium $\left(4.6 \pm 0.8 \times 10^{6} ; P<0.05\right)$. In the interstitium of the lung, LPS stimulation caused an increase in PMNs in all groups (control: $1 \pm 0.1 \times 10^{6}$; LPS treated: $5.1 \pm 1.8 \times 10^{6}$; hemin: $3.5 \pm 1 \times 10^{6} ; \quad$ hemin + SnPP: $8.6 \pm 2.9 \times 10^{6} ;$ all $P<0.05)$. Hemin treatment significantly reduced PMN influx, and the addition of tin-protophorphyrin-IX (SnPP) further augmented PMN migration, confirming our findings from immunohistology. LPS inhalation caused a rise in PMN counts in the bronchoalveolar lavage (BAL) of all groups (control: $0.04 \times 10^{6}$; LPS treated: $1.9 \pm 0.5 \times 10^{6}$; hemin: $1.3 \pm 0.4 \times 10^{6}$; hemin + SnPP: $2.8 \pm 0.9 \times 10^{6}$; all $P<0.05$ ). The activation of HO-1 significantly reduced and the inhibition increased PMN influx, highlighting the anti-inflammatory potential of HO-1 in our model.

In the HO- $1^{\text {flox/flox }}$ mice, LPS inhalation caused a rise of PMN counts in all three compartments of all groups (Figure 3b). In the intravascular compartment, the inhibition of HO-1 further increased PMNs compared with LPS-treated group $\left(6 \pm 0.7 \times 10^{6}\right.$ vs. $\left.3.1 \pm 1.2 \times 10^{6} ; P<0.05\right)$. The activation of HO-1 did not lead to any difference in the number of PMNs attached to the endothelium. Surprisingly, HO-1 activation also resulted in a decrease in PMN influx in the interstitium of these mice comparable to the wild-type animals $\left(2.6 \pm 0.8 \times 10^{6}\right.$ vs. $\left.5.4 \pm 1.4 \times 10^{6} ; \quad P<0.05\right)$, indicating the pivotal role of nonmyeloid HO-1 for the anti-inflammatory effect of this enzyme. SnPP enhanced the interstitial PMN counts $\left(7.4 \pm 2.6 \times 10^{6} ; P<0.05\right)$. The results of the BAL counts supported the hypothesized crucial tissue-specific role of HO-1, as hemin reduced the PMN counts in the BAL $\left(1.2 \pm 0.4 \times 10^{6}\right.$ vs. $\left.2.3 \pm 0.2 \times 10^{6} ; \quad P<0.05\right)$ and SnPP correspondingly increased counts $\left(3.2 \pm 0.8 \times 10^{6} ; P<0.05\right)$.

In summary, the only difference in the in vivo PMN migration assay results between the wild-type and HO- $1^{\text {flox/flox }}$ mice was in the intravascular compartment. The stimulation of HO-1 decreased PMN counts in the wild-type but not in the floxed mice. Considering that the PMN counts in the interstitium and the alveolar space were comparable between the two groups after hemin treatment, the difference in the intravascular compartment did not further influence PMN migration.

\section{Microvascular permeability}

As an indicator of capillary leakage, the Evans blue levels were determined in the lungs of the wild-type and HO- $1^{\text {flox/flox }}$ mice. Neither hemin nor SnPP administration to the groups in the absence of LPS inhalation induced any change in Evans blue extravasation, and these results were identical to those of the control (Supplementary Figure S4). LPS inhalation significantly enhanced microvascular permeability in the LPStreated group ( $208 \pm 35$ vs. $94 \pm 20 \mu \mathrm{gg}^{-1}$ lung; $P<0.05$; Figure 4). The activation of HO-1 prevented the LPS-induced increase in Evans blue extravasation and was even comparable to control group without LPS inhalation $\left(76 \pm 25 \mu \mathrm{g} \mathrm{g}^{-1}\right.$ lung; $P<0.05$ ), indicating the distinct role of $\mathrm{HO}-1$ in microvascular 
a
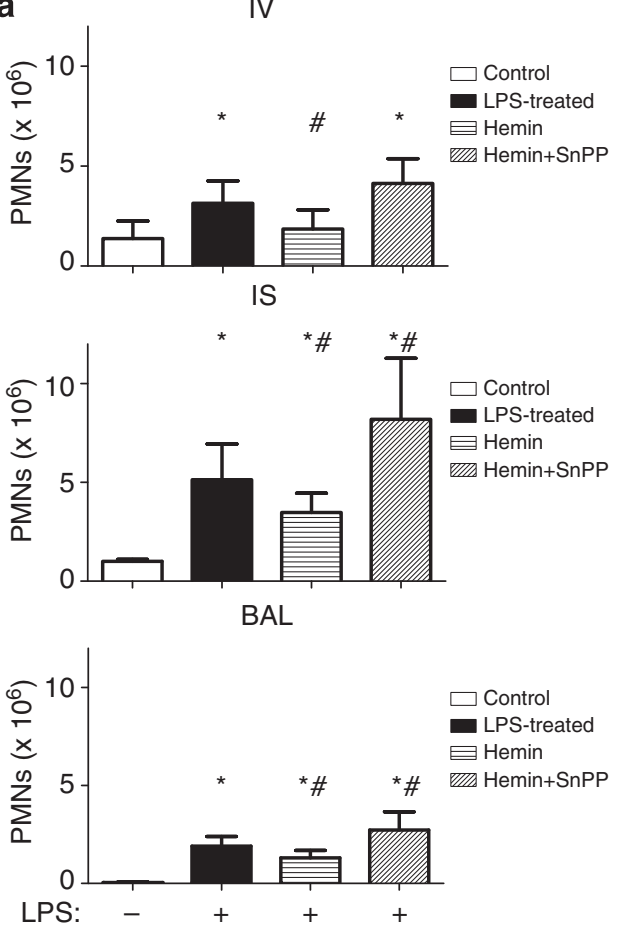

b
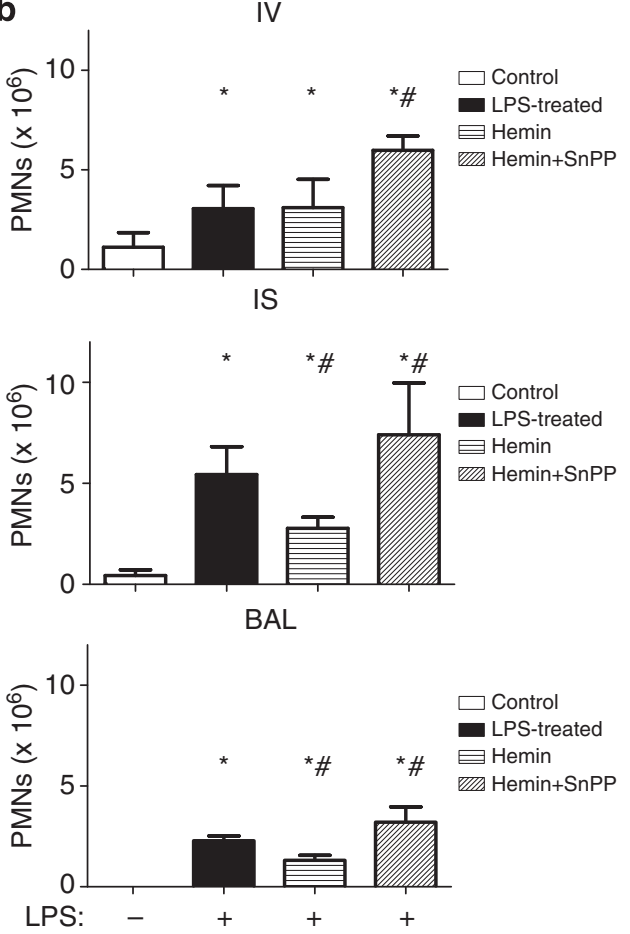

Figure 3 Migration of polymorphonuclear leukocytes (PMNs) into the different compartments of the lung. Migration of PMNs in the (a) wild-type and (b) HO-1 flox/flox mice. Lipopolysaccharide (LPS) exposure increased intravascular (IV) and also PMNs in the other compartments of the lung (BAL, bronchoalveolar lavage; IS, interstitial) in both strains. Mean \pm s.d.; control group without LPS inhalation, $n=4$; other groups, $n \geq 6$ (a)/ $n \geq 7$ (b); ${ }^{\star} P<0.05$ compared with the control group without LPS inhalation; ${ }^{\#} P<0.05$ compared with the LPS-treated group. HO-1, heme oxygenase-1; SnPP, tin-protophorphyrin-IX.

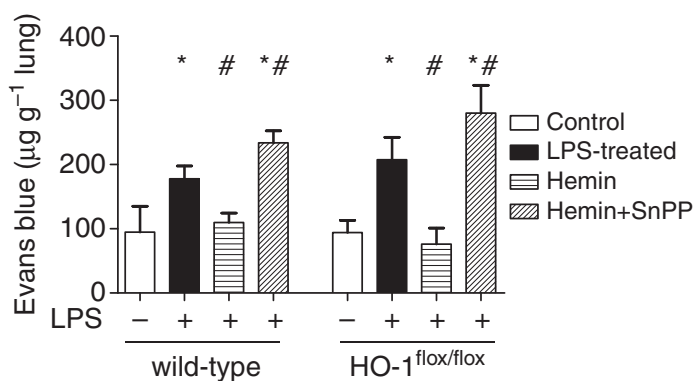

Figure 4 Heme oxygenase-1 (HO-1) stimulation reduced microvascular permeability in the wild-type and $\mathrm{HO}-1^{\text {flox/flox }}$ animals. At $6 \mathrm{~h}$ after lipopolysaccharide (LPS) inhalation, a significant increase in the Evans blue concentration was detected. Mean \pm s.d.; $n \geq 5$; ${ }^{*} P<0.05$ compared with the corresponding control group without LPS inhalation; ${ }^{\#} P<0.05$ compared with the corresponding LPS-treated group of the same strain. SnPP, tin-protophorphyrin-IX.

permeability. In contrast, the inhibition of HO-1 increased significantly microvascular permeability compared with the LPS-treated group ( $280 \pm 43 \mu \mathrm{gg}^{-1}$ lung; $P<0.05$ ).

In the HO- ${ }^{\text {flox/flox }}$ mice, we observed similar results of Evans blue extravasation, including a significant increase after LPS inhalation (178 \pm 20 vs. $95 \pm 41 \mu \mathrm{gg}^{-1}$ lung; $\left.P<0.05\right)$. Hemin protected from capillary leakage in these mice as well $(110 \pm 15$; $P<0.05$ ), and the inhibition of HO-1 led to an increase (234 $\pm 19 \mu \mathrm{g} \mathrm{g}^{-1}$ lung; $\left.P<0.05\right)$ of microvascular permeability, emphasizing the pivotal role of nonmyeloid HO-1 on endothelial integrity.
Chemokine release in the wild-type and $\mathrm{HO}-1^{\text {flox/flox }}$ mice The chemokine levels of CXCL1, CXCL2/3, tumor necrosis factor$\alpha$ (TNF $\alpha$ ), and interleukin 6 (IL6) were measured in the BAL of both strains. Neither the inhibition nor the activation of HO-1 altered the baseline chemokine levels (Supplementary Figure S5). LPS inhalation significantly increased the release of all chemokines in all groups (all $P<0.05$ ). After the activation of $\mathrm{HO}-1$, the level of the potent neutrophil attractant CXCL1 was reduced in the wildtype and HO-1 $1^{\text {flox/flox }}$ mice, whereas inhibition of the enzyme caused a significant increase in both strains (all $P<0.05$; Figure 5). Remarkably, the CXCL1 levels were significantly lower in the HO- $1^{\text {flox/lox }}$ compared with wild-type mice $(2,447 \pm 71$ vs. $\left.3,757 \pm 820 \mathrm{pg} \mathrm{ml}^{-1} ; P<0.05\right)$, but the relative HO-1-dependent changes were equivalent between the two strains.

The levels of the chemoattractant TNF $\alpha$ were significantly higher in the HO- ${ }^{\text {flox/llox }}$ mice than in the wild-type animals $\left(2,382 \pm 325\right.$ vs. $\left.1,564 \pm 275 \mathrm{pg} \mathrm{ml}^{-1} ; P<0.05\right)$. In both strains, hemin reduced the TNF $\alpha$ levels (all $P<0.05$ ), and the addition of SnPP reversed this anti-inflammatory effect.

In the wild-type and HO- $1^{\text {flox/flox }}$ mice, the CXCL2/3 and IL6 levels were both reduced via the activation of HO-1 (all $P<0.05$ ), highlighting the anti-inflammatory potential of this enzyme and explaining the results from our in vivo migration assay with reduced PMNs in the alveolar system. Again, the inhibition of HO-1 inverted the reduction of both chemokines.

The major PMN chemoattractants are CXCL1 and CXCL2/3. 27,28 To determine whether CXCL1 or CXCL2/3 
has the higher impact on reducing PMN migration after HO-1 stimulation, we performed an in vitro PMN migration assay through a monolayer of human pulmonary epithelial cells (Figure 5b). Isolated human PMNs migrated through a chemotactic gradient of either CXCL1 or CXCL2/3. HO-1 stimulation on epithelial cells reduced only CXCL1-related PMN migration. In concordance with the fact that CXCL1 is mainly secreted by pulmonary epithelium, ${ }^{28,29}$ this further emphasizes the critical role of nonmyeloid HO- 1.

In addition, we investigated the release of CXCL1 and CXCL2/3 by murine alveolar macrophages, PMNs, and pulmonary epithelial cells (Figure 5c). CXCL1 was also secreted by alveolar macrophages, but to a much higher degree by the epithelium. In this setting, PMNs did not release CXCL1 (data not shown). HO-1 stimulation was effective when the epithelium was treated but had no effect on alveolar macrophages, confirming our results from the in vivo PMN migration assay. CXCL2/3 was secreted by alveolar macrophages and to a very little extent by PMNs. Pulmonary epithelium did not release this chemokine (data not shown). Nevertheless, hemin did not influence the release of the chemokine in myeloid cells, confirming our findings from the in vitro PMN migration assay and also the in vivo PMN migration.

\section{Effect of HO-1 on cytoskeletal remodeling}

We stained pulmonary epithelial cells for F-actin to determine the impact of HO-1 on cytoskeletal remodeling as one critical parameter of pulmonary barrier function (Figure 6). LPS exposure induced stress fibers, whereas the activation of $\mathrm{HO}-1$ reduced cytoskeletal remodeling, confirming the pivotal role of HO-1 in stabilizing the pulmonary barrier and explaining our results from the in vivo PMN migration assay.

\section{The impact of HO-1 on oxidative burst}

We determined the impact of HO-1 on the release of oxidative products from PMNs and mononuclear cells of the wild-type and HO- $1^{\text {flox/flox }}$ mice. Depletion of HO-1 reduced oxidative burst in PMNs and mononuclear cells (Figure 7) as suggested by others. ${ }^{30}$

\section{Reduced phosphorylation of nuclear factor-кB (NFKB) after HO-1 stimulation}

HO-1 was activated in the LPS-exposed mice. LPS inhalation increased the phosphorylation and, therefore, the activation of the NFKB subunits p65 and p52. The phosphorylation of these
NFкB subunits initiate the transcription of various inflammatory genes, especially inflammatory cytokines/chemokines. ${ }^{31}$

The activation of HO- 1 reduced the active forms of NFKB, thereby suppressing the inflammatory pathway (Figure 8a). No differences were observed between the two strains. These findings support our chemokine data with a hemin-induced reduction in the inflammatory chemokine levels in both strains.

\section{Influence of HO-1 on tight junction formation}

To further determine the influence of nonmyeloid HO-1 on pulmonary barrier function, we investigated the influence of hemin on the tight junction proteins zonula occludens- 1 (ZO-1) and on occludin (Figure 8b). ZO-1 is localized in tight junctions in epithelial and endothelial cells, and additionally at adherens junctions. ${ }^{32-34}$ Occludin is a transmembrane protein and forms a complex with ZO- $1 .{ }^{35}$

After LPS inhalation, ZO-1 and occludin expression decreased. The administration of hemin increased again the expression of ZO-1 and occludin. These findings confirm the pivotal role of nonmyeloid HO-1 on stabilization of pulmonary barrier function.

ZO-1 links tight junctions to the actin cytoskeleton by binding the tight junction transmembrane proteins and actin, ${ }^{35}$ and hence the finding of this assay confirms our results from cytoskeletal remodeling.

\section{The enzymatic activity of HO-1}

To verify that our results depended on the enzyme HO- 1 and to further distinguish between the wild-type and HO- $1^{\text {flox/flox }}$ mice, we determined the activity of this enzyme in the lungs and the liver of both strains. In the liver, LPS inhalation increased HO- 1 activity in the wild-type mice $(49 \pm 18$ vs. $24 \pm 9 \mathrm{pg} \mathrm{ml}^{-1} \mathrm{~h}^{-1} ; P<0.05$; Figure 9a) and HO- $1^{\text {flox/flox }}$ mice (55 \pm 9 vs. $19 \pm 7 \mathrm{pg} \mathrm{ml}^{-1} \mathrm{~h}^{-1} ; P<0.05$; Figure 9b). Hemin significantly increased the activity of this enzyme in both strains even in the absence of an inflammatory stimulus (wild type: $82 \pm 31$; HO- $1^{\text {flox/flox }}: 99 \pm 16 \mathrm{pg} \mathrm{ml}^{-1} \mathrm{~h}^{-1} ; P<0.05$ ), and the activity of the enzyme was further enhanced by LPS inhalation (wild type: $129 \pm 29 ; \quad \mathrm{HO}-1^{\text {flox/flox }}$ : $137 \pm 35 \mathrm{pg} \mathrm{ml}^{-1} \mathrm{~h}^{-1}$; $P<0.05)$. The inhibition of HO-1 decreased the activity of this enzyme and completely abolished the LPS-induced increase in the activity of HO-1 (wild type: $18 \pm 10$; HO- $1^{\text {flox/flox }}$ : $\left.3 \pm 6 \mathrm{pg} \mathrm{ml}^{-1} \mathrm{~h}^{-1} ; P<0.05\right)$.

In the lungs, LPS inhalation also increased HO-1 activity in the wild-type mice (Figure 9c) and $\mathrm{HO}-1^{\text {flox/flox }}$ mice (Figure 9d) (wild type: $152 \pm 21$ vs. $104 \pm 13 \mathrm{pg} \mathrm{ml}^{-1} \mathrm{~h}^{-1}$;

Figure 5 Influence of heme oxygenase (HO)-1 on chemokine levels of different cell types and related polymorphonuclear leukocyte (PMN) migration. (a) Chemokine release in the wild-type and HO-1 ${ }^{\text {flox/flox }}$ animals. All animals inhaled lipopolysaccharide (LPS). The activation of HO-1 caused an equivalent reduction of each chemokine in wild-type and HO- flox/flox mice. Mean \pm s.d.; wild-type $n \geq 4 ; \mathrm{HO}-1^{\text {flox/flox }} n \geq 7 ;{ }^{*} P<0.05$ compared with the control group of the corresponding strain; ${ }^{*} P<0.05$ compared with the wild-type control. IL6, interleukin 6 ; TNF $\alpha$, tumor necrosis factor- $\alpha$. (b) The effect of CXCL1 and CXCL2/3 on the in vitro PMN migration with human cells. Human pulmonary epithelial cells were treated with hemin and isolated human PMNs migrated through a chemotactic gradient of either CXCL1 or CXCL2/3. Mean \pm s.d.; $n \geq 4 ;{ }^{*} P<0.05$ compared with the control group without chemokine; ${ }^{\#} P<0.05$ compared with the corresponding control with chemokine. (c) Chemokine release of murine alveolar macrophages, PMNs, and murine pulmonary epithelial cells. PMNs were isolated from the bone marrow, whereas macrophages and epithelial cells were cultivated until reaching confluence. Cells were treated with $5 \mu \mathrm{m}$ hemin and stimulated with LPS for $4 \mathrm{~h}$. Mean $\pm \mathrm{s}$.d.; $n \geq 4 ;{ }^{*} P<0.05$ compared with the unstimulated control group; ${ }^{\#} P<0.05$ compared with LPS-treated cells. 
a

CXCL1
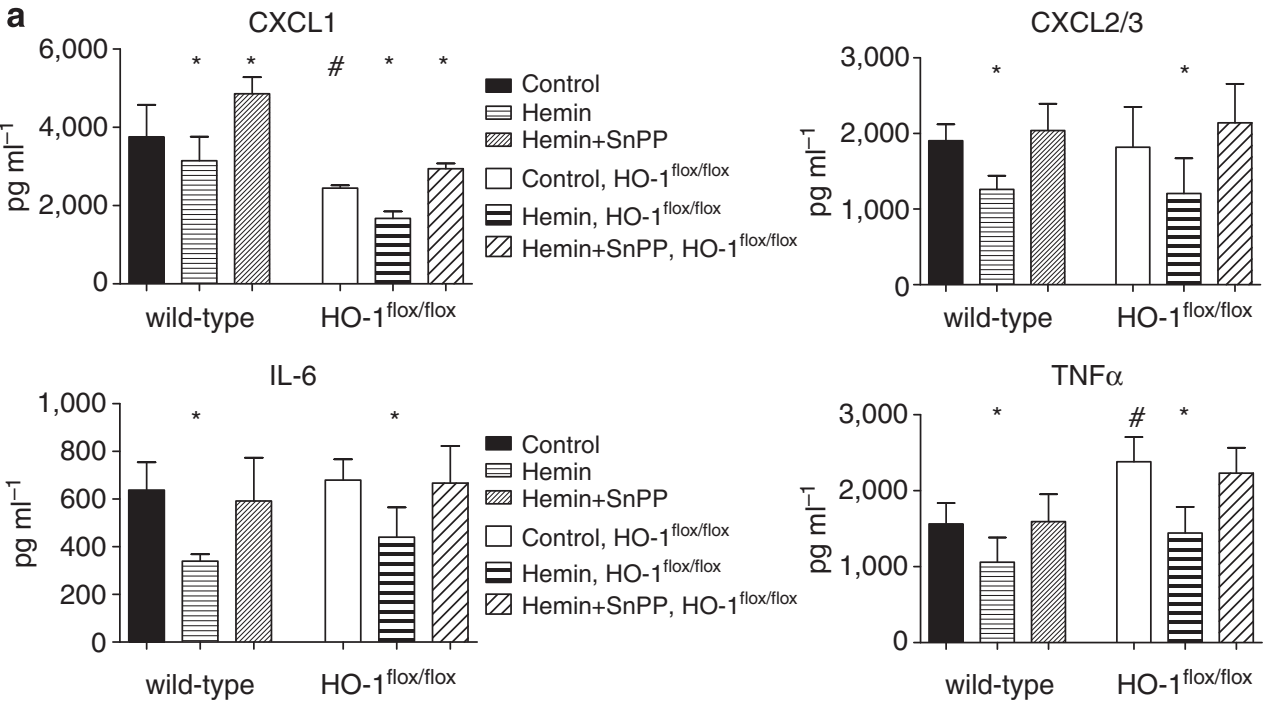

b

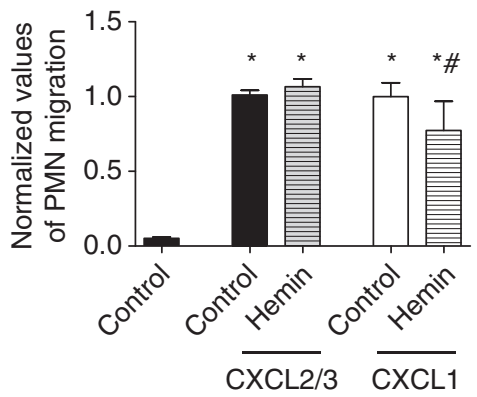

C

CXCL1
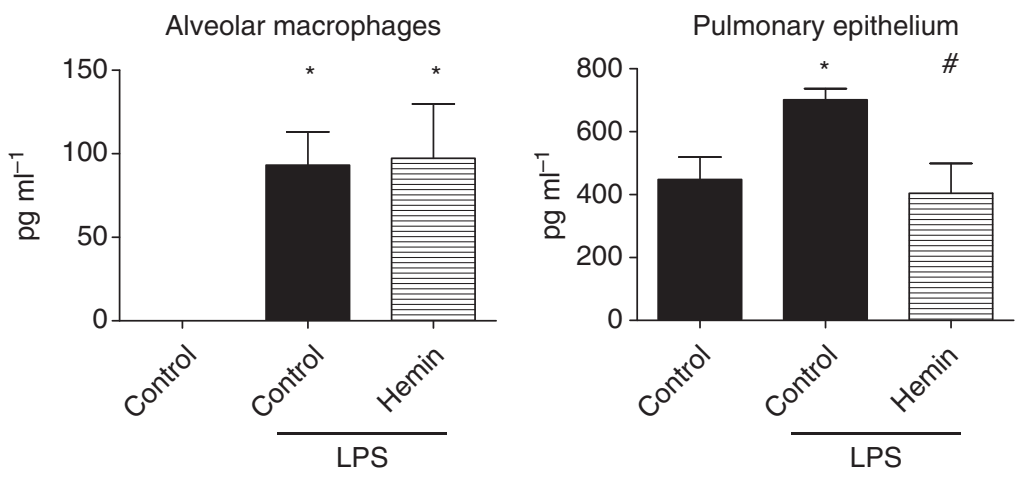

CXCL2/3
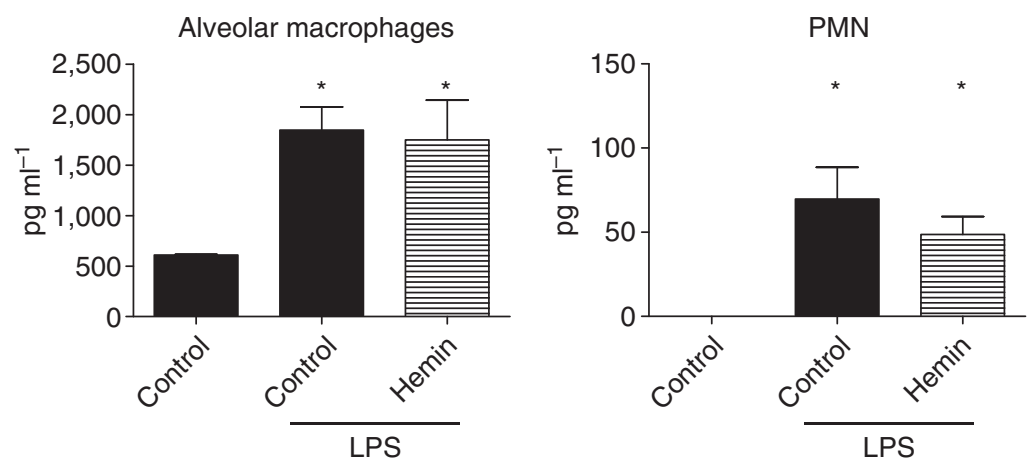

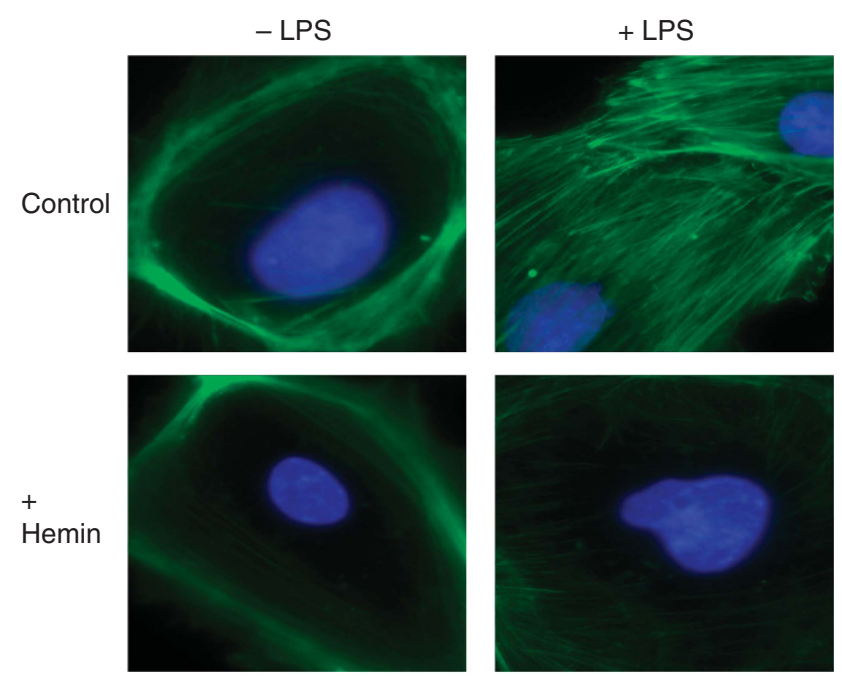

Figure 6 Influence of heme oxygenase-1 (HO-1) on cytoskeletal remodeling. Pulmonary epithelial cells were treated with hemin and/or stimulated with lipopolysaccharide (LPS). The formation of F-actin (green) was determined. The images are representative of four experiments (original magnification $\times 63$ ).

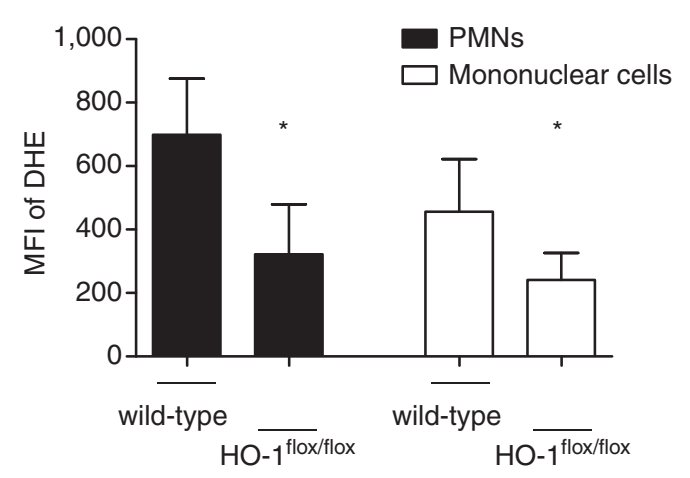

Figure 7 Oxidative burst in polymorphonuclear leukocytes (PMNs) and mononuclear cells of the wild-type and $\mathrm{HO}-1^{\text {flox/flox }}$ mice. Cells were isolated from the bone marrow of the animals and were stimulated with phorbol myristate acetate (PMA; $100 \mathrm{ng} \mathrm{ml}^{-1}$ ) to induce oxidative burst. As an indicator of oxidative stress, the mean fluorescence intensity (MFI) of dihydroethidium (DHE) staining was measured in both cell types. Mean \pm s.d.; $n=6$. ${ }^{\star} P<0.05$ compared with the wild-type mice. HO-1, heme oxygenase- 1 .

HO- $1^{\text {flox/flox }}: 147 \pm 13$ vs. $75 \pm 44 \mathrm{pg} \mathrm{ml}^{-1} \mathrm{~h}^{-1}$; all $\left.P<0.05\right)$. In contrast to our findings regarding $\mathrm{HO}-1$ activity in the liver, the administration of hemin did not increase $\mathrm{HO}-1$ activity, but the basal activity of $\mathrm{HO}-1$ in the lungs was significantly higher than that in the liver $\left(104 \pm 13\right.$ vs. $\left.24 \pm 9 \mathrm{pg} \mathrm{ml}^{-1} \mathrm{~h}^{-1} ; P<0.05\right)$. Intraperitoneal hemin administration and LPS inhalation enhanced the activity of this enzyme in both strains, similar to the LPS-treated group (wild type: $186 \pm 23$; HO- ${ }^{\text {flox/flox }}$ $192 \pm 40 \mathrm{pg} \mathrm{ml}^{-1} \mathrm{~h}^{-1}$; all $\left.\mathrm{P}<0.05\right)$. The inhibition of HO-1 decreased its activity such that levels of $\mathrm{HO}-1$ were comparable to those of the controls in the absence of LPS inhalation and were significantly lower compared with those of the LPS-treated group (wild type: $94 \pm 11$; $\mathrm{HO}-1^{\text {flox/flox }} 57 \pm 16 \mathrm{pg} \mathrm{ml}^{-1} \mathrm{~h}^{-1}$; all $P<0.05)$.

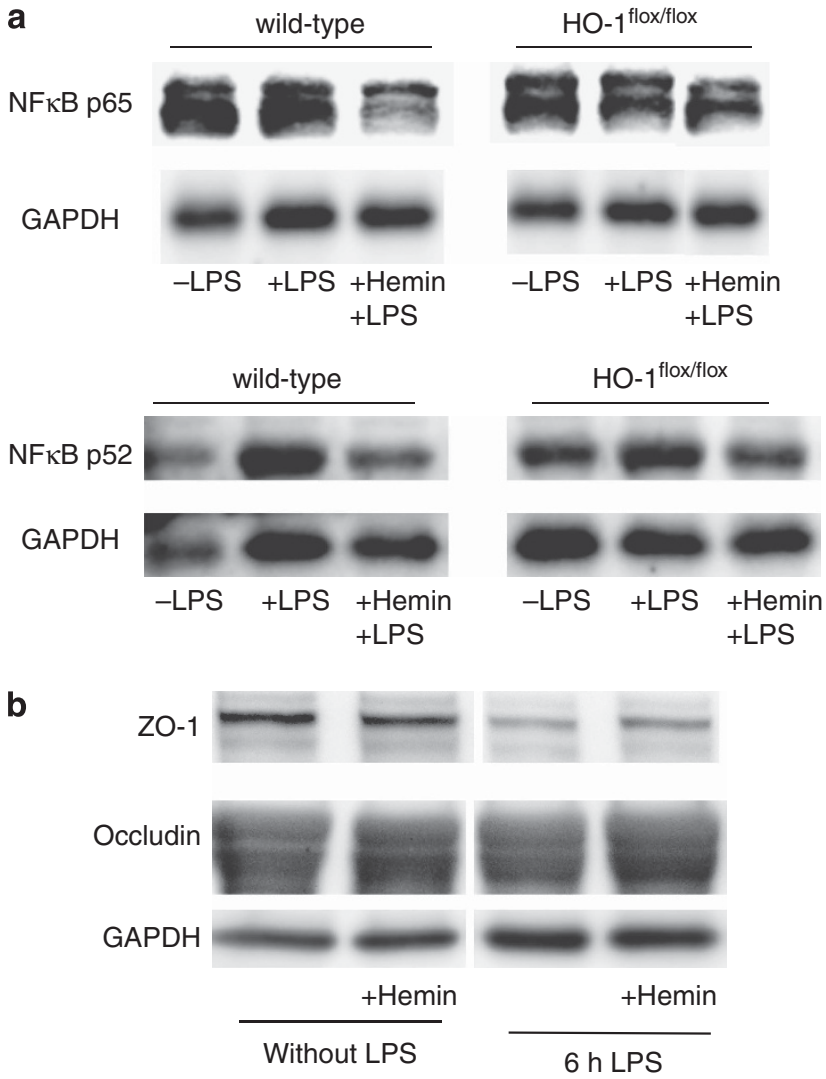

Figure 8 Heme oxygenase-1 (HO-1) reduced the activation of the inflammatory transcription factor and increased tight junction proteins. (a) Role of HO-1 in the phosphorylation of nuclear factor-кB (NFkB). HO-1 was induced in mice using hemin. The phosphorylation of the two NFK subunits 65 and 52 in the lungs of the wild-type and $\mathrm{HO}-1^{\text {flox/flox }}$ mice was determined in the presence and absence of lipopolysaccharide (LPS) inhalation and hemin treatment $(n=4)$. (b) Impact of HO-1 on the formation of tight junctions. Mice were treated with hemin and $6 \mathrm{~h}$ of LPS, and the expression of zonula occludin (ZO)-1 and -2, and occludin investigated $(n=4)$.

\section{Hemin administration remained effective after LPS inhalation}

To further evaluate the anti-inflammatory effects of hemin, we performed an in vivo migration assay in which hemin was administered simultaneously with or $4 \mathrm{~h}$ after LPS inhalation (Figure 10). The simultaneous administration of hemin and LPS did not reduce the number of PMNs attached to the endothelium or in the lung intersitium; however, when hemin was administered $4 \mathrm{~h}$ after LPS inhalation, the interstitial PMN counts were further reduced. No differences in PMN influx into the BAL was observed between the hemin-treated groups. Therefore, HO- 1 activation was also effective when initiated $4 \mathrm{~h}$ after LPS inhalation, emphasizing the clinical potential of activating HO-1.

\section{The nebulization of hemin reduced the required dose for its anti-inflammatory effects on PMN migration}

To reduce possible side effects caused by systemic administration, we applied hemin topically via nebulization and compared the effects of this treatment with hemin administered 

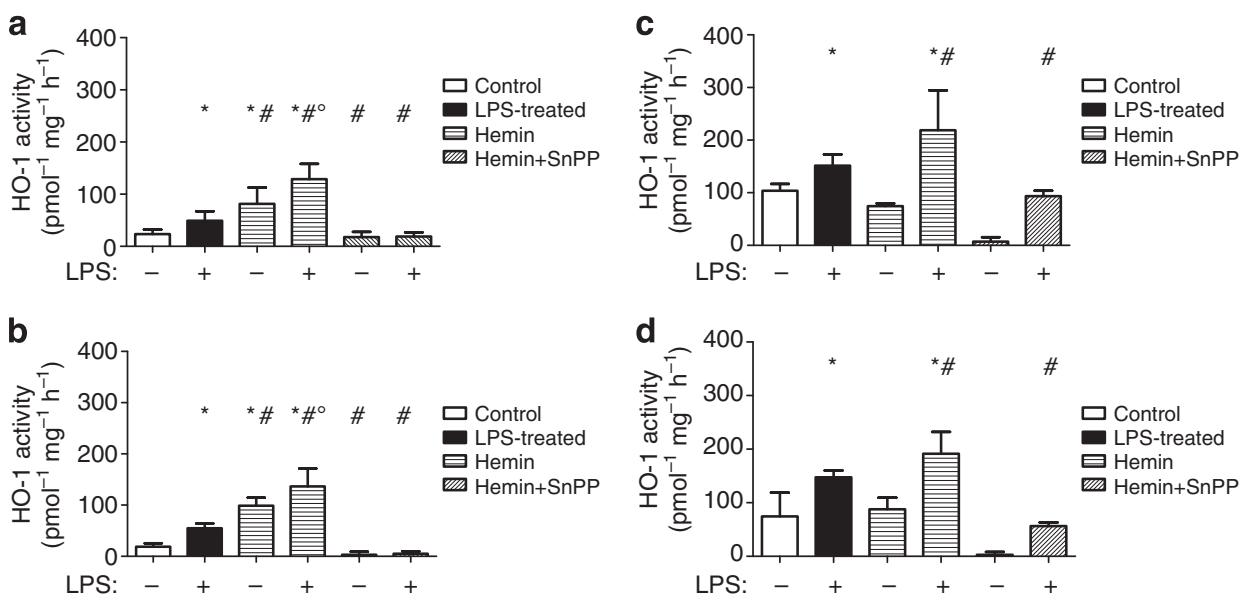

Figure 9 The enzymatic activity of heme oxygenase-1 (HO-1) in the liver and the lungs of the wild-type and HO- $1^{\text {flox/flox }}$ mice. Lipopolysaccharide (LPS) exposure induced a significant rise of HO-1 activity in the liver (a: wild type, b: HO- ${ }^{\text {flox/flox }}$ ) and lungs (c: wild type, d: HO-1 $1^{\text {floxflox }}$ ). SnPP, tin-protophorphyrin-IX. Hemin treatment increased and inhibition of HO-1 decreased the enzymatic activity. Mean $\pm \mathrm{s}$.d.; $n \geq 4 ;{ }^{\star} P<0.05$ compared with the control group without LPS inhalation; ${ }^{\#} P<0.05$ compared with the LPS-treated group; ${ }^{\circ} P<0.05$ compared with hemin-treated group without LPS.

intraperitoneally (IP) at a dose of $80 \mu \mathrm{mol} \mathrm{kg}{ }^{-1}$. In contrast to our previous findings, PMNs attached to the endothelium under these conditions were not reduced by the IP administration of hemin. The PMN counts in the intravascular compartment displayed some variability, as this parameter depends on several factors (the circulating cell counts, status of the pulmonary vasculature, completeness of flushing, and so on) and are therefore a limitation of our technique.

Via nebulization, we were able to reduce the required dose of hemin to $2 \mu \mathrm{mol} \mathrm{kg}^{-1}$ (dilution factor of 1:40) to exert a comparable effect on the interstitial PMN counts (Figure 11a). In this group, $\mathrm{PMN}$ influx into the alveolar system was even further reduced $\left(0.6 \pm 0.4 \times 10^{6}\right.$ vs. $\left.1.7 \pm 0.5 ; P<0.05\right)$, indicating the advantage of local hemin administration. Even at a further reduction of hemin to $0.4 \mu \mathrm{mol} \mathrm{kg}{ }^{-1}$ (dilution factor of 1:200), the anti-inflammatory effect of hemin was still notable in the BAL and PMN migration was reduced compared with hemin intraperitoneally $\left(1.1 \pm 0.2 \times 10^{6} ; P<0.05\right)$. At this concentration, the number of migrated PMNs was increased in the interstitium compared with the LPS-treated group, most likely because the systemic effect was too low.

Influence of nebulized hemin on the release of chemokines The nebulization of hemin $\left(2 \mu \mathrm{mol} \mathrm{kg}^{-1}\right)$ reduced the levels of all four chemokines to a comparable extent as intraperitoneal hemin administration (Figure 11b). In fact, TNF $\alpha$ levels following nebulized hemin administration were significantly lower compared with intraperitoneal hemin administration $(0.7 \pm 0.2$ vs. $0.9 \pm 0.05 ; P<0.05)$, confirming our results from the PMN migration assay.

\section{Microvascular permeability was reduced by nebulized hemin}

Nebulized hemin administration at a reduced dose of $2 \mu \mathrm{mol} \mathrm{kg}^{-1}$ effectively stabilized endothelial barrier function, and this effect was comparable to IP hemin administration (Figure 11c).

\section{HO-1 activity in the lungs after nebulization of hemin}

In the wild-type animals, nebulized hemin administration caused an equivalent increase in HO-1 activity in the lungs to IP hemin administration, confirming our findings from the in vivo migration assay (Figure 11d).

\section{DISCUSSION}

Several studies of the anti-inflammatory effects of HO-1 on pulmonary inflammation have been published, ${ }^{11,19,36}$ although the underlying mechanisms require elucidation. Therefore, we investigated the role of myeloid and nonmyeloid HO-1 in terms of LPS-induced lung inflammation. In our study, nonmyeloid HO-1 was crucial for ameliorating PMN migration to different compartments of the lung, reducing the chemokine levels and maintaining endothelial integrity.

The importance of the enzyme HO-1 for humans is highlighted by two documented cases of children exhibiting HO-1 deficiency who presented with profound endothelial damage and sensitivity to oxidative and inflammatory injury and who ultimately died during childhood. ${ }^{37,38}$ Similarly, HO-1 knockout mice (HO-1 ${ }^{-l-}$ ) exhibited enhanced sensitivity to oxidative stress and increased susceptibility to injury. ${ }^{39,40}$ $\mathrm{HO}-1^{-1-}$ mice are less fertile and typically experience intrauterine fetal death. ${ }^{41} \mathrm{HO}-1^{-1-}$ mice generally have reduced body weight and are prone to develop vasculitis, atherosclerosis, anemia, and hepatic and renal iron accumulation, leading to tissue damage and chronic inflammation, along with organ injury/failure. ${ }^{39,42-44} \mathrm{HO}-1^{-1-}$ mice typically die within the first 6 months. ${ }^{44}$ Therefore, we decided to use HO- $1^{\text {flox/flox }}$ mice that lack leukocytic HO-1 in this study to ensure that our results were not influenced by genetically caused illnesses. The HO- $1^{\text {flox/flox }}$ mice did not exhibit apparent abnormalities and were viable and fertile. 
In this study, we discovered a previously unknown critical role of nonmyeloid HO-1 in terms of PMN migration in response to pulmonary injury. The findings of Tzima et al. ${ }^{44}$ highlight the results of our studies. They also used HO- $1^{\text {flox/flox }}$ mice that lack myeloid HO-1. Tzima et al. ${ }^{44}$ isolated peritoneal macrophages from $\mathrm{HO}-1^{\text {flox/flox }}$ mice, stimulated them with LPS, and determined the phosphorylation levels of the transcription factor NFKB and mitogen-activated protein kinases and the release of different chemokines. In agreement with our data concerning neutrophils, they observed no differences between macrophages from the $\mathrm{HO}-1^{\text {flox/flox }}$ and control mice. The findings of that group and our findings in this

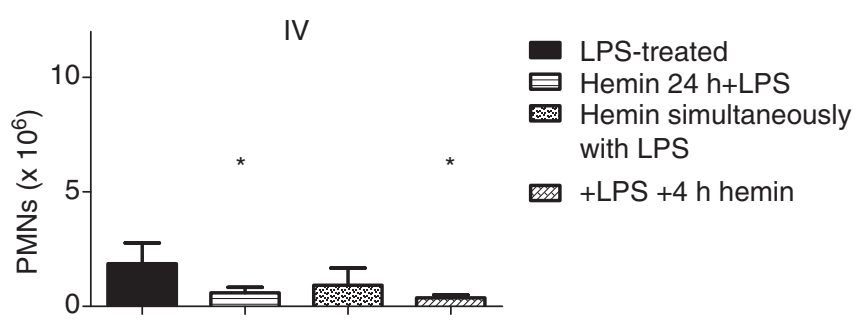

IS

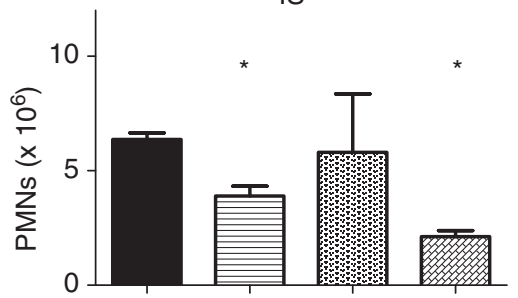

- LPS-treated 曰 Hemin $24 \mathrm{~h}+\mathrm{LPS}$ Hemin simultaneously with LPS

+LPS $+4 \mathrm{~h}$ hemin

BAL

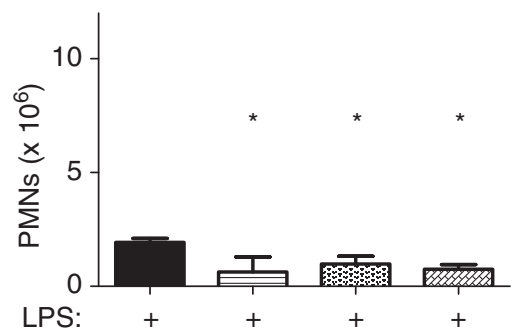

study appear to contrast with those of other in vitro studies, in which isolated macrophages displayed a markedly inhibited immune response and reduced cytokine levels following HO-1 stimulation or overexpression. ${ }^{45,46}$ The reason for this discrepancy might be that leukocytes do respond to HO-1 activation but that nonmyeloid HO-1 appears to be more relevant and easily compensates for the lack of leukocytic HO1. Along these lines, our HO-1 activity measurements did not reveal any overall differences between the wild-type and HO$1^{\text {flox/flox }}$ mice.

We observed enhanced phosphorylation of NFאB after LPS stimulation as described in the literature. ${ }^{47}$ In this study, the stimulation of $\mathrm{HO}-1$ decreased $\mathrm{NF \kappa B}$ phosphorylation and might have inhibited the transcription of inflammatory chemokines, explaining the reduced release of chemokines. In contrast to previously published studies, ${ }^{44}$ we investigated the entire lung rather than focusing on isolated macrophages.

We detected reduced oxidative burst activity in PMNs and macrophages isolated from the bone marrow of HO- $1^{\text {flox/flox }}$ mice compared with those of wild-type animals. This result is in accordance with the findings of Walther et al. ${ }^{30}$ They isolated PMNs from malaria patients and determined oxidative burst activity after inhibiting $\mathrm{HO}-1$, which significantly reduced the release of oxidative products. We also investigated the previously described impact of the loss of HO-1 on functional defects of macrophages and determined the levels of inflammatory gene expression. ${ }^{44,48,49}$ We determined the expression of inducible nitric oxide synthase, RANTES (chemokine ligand 5 (CCL5)), monocyte chemotactic protein-1 (also known as chemokine ligand 2 (CCL2)), and matrix metallopeptidase-9 (data not shown) in the lungs of mice. In the wild-type animals, the expression of all markers increased in response to LPS inhalation, and this increase was enhanced by HO-1 stimulation. In contrast, all inflammatory gene levels were nearly undetectable in the HO- $1^{\text {flox/flox }}$ mice.

Together, these data confirm previous results showing that myeloid HO-1 is involved in inflammatory responses-at least at the cellular level. However, our study showed for the first time that nonmyeloid HO-1 is required to regulate PMN trafficking and endothelial integrity. In our model, this activity of HO-1 appears to be independent of myeloid HO-1 based on all of our functional experiments.

The impact of HO-1 on the increased formation of tight junctions after inflammation further highlights our findings from cytoskeletal remodeling. The reduction in stress fibers, a

Figure 11 Nebulized administration of the heme oxygenase-1 (HO-1) activator hemin. (a) Topical hemin administration and its effect on

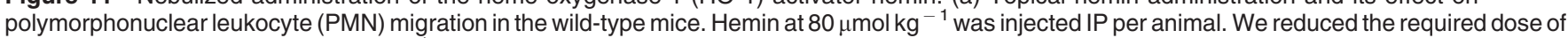
nebulized hemin to 2 and $0.4 \mu \mathrm{mol} \mathrm{kg}{ }^{-1}$. BAL, bronchoalveolar lavage; IS, interstitial; IP, intraperitoneally; IV, intravascular; neb, nebulized. Control group without lipopolysaccharide (LPS), $n=4$; other groups, $n \geq 7 ;{ }^{*} P<0.05$ compared with the control group; ${ }^{\prime} P<0.05$ compared with the LPS-treated group; ${ }^{\circ} P<0.05$ compared with the hemin IP group. (b) Effects of topical hemin administration on the release of chemokines in the wild-type animals. IL6, interleukin 6; TNF $\alpha$, tumor necrosis factor- $\alpha$. The nebulized administration of hemin (neb) at a reduced dose of $2 \mu \mathrm{mol} \mathrm{kg}{ }^{-1}$ led to a comparable decrease in the levels of all four chemokines to the IP administration of hemin. Mean \pm s.d.; $n \geq 4 ;{ }^{*} P<0.05$ compared with the control group without LPS inhalation; ${ }^{\#} P<0.05$ compared with the LPS-treated group; ${ }^{\circ} P<0.05$ compared with the hemin IP group. Influence of nebulized hemin on (c) microvascular permeability and (d) HO-1 activity. Mean \pm s.d.; $n \geq 4$; ${ }^{*} P<0.05$ compared with the control group without LPS inhalation; ${ }^{*} P<0.05$ compared with the LPStreated group. 
marker of pulmonary barrier function, was remarkable in endothelial cells after the stimulation of HO-1. Both results indicate the predominant role of nonmyeloid HO-1.
Tzima et al. ${ }^{44}$ postulated, after their aforementioned findings in peritoneal macrophages from HO- $1^{\text {flox/flox }}$, an early phase of inflammation that might be independent of leukocytic HO-1. a

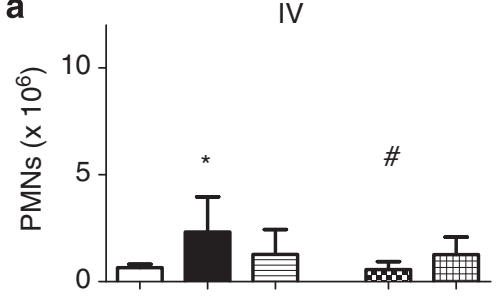

IS

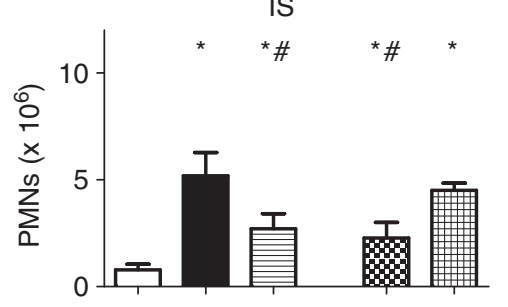

BAL

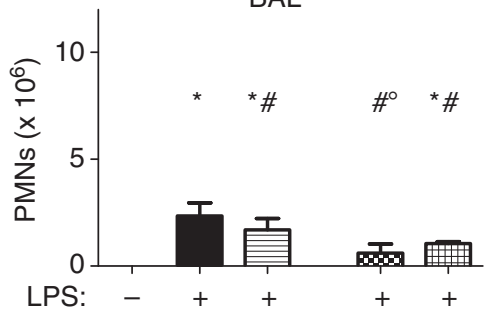

CXCL1

b

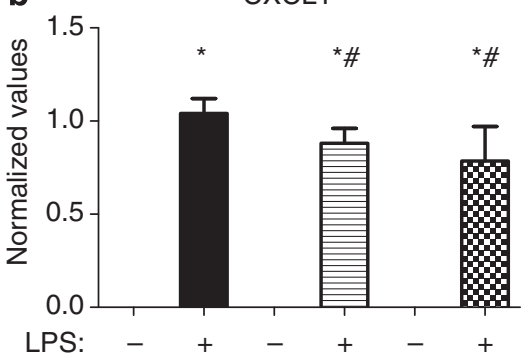

IL6

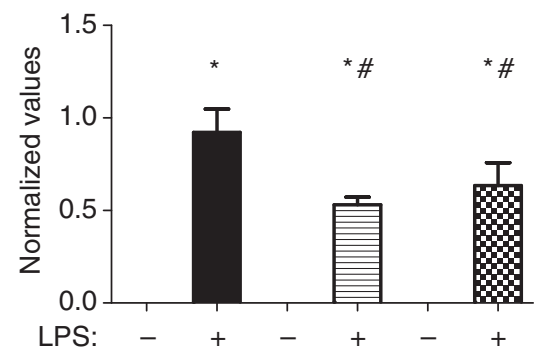

$\square$ Control LPS-treated $\mathbf{B}$ Hemin neb

$\square$ Control

LPS-treated

口Hemin IP $\left(80 \mu \mathrm{mol} \mathrm{kg}^{-1}\right)$

요 Hemin neb $\left(2 \mu \mathrm{mol} \mathrm{kg}^{-1}\right)$

Hemin neb $\left(0.4 \mu \mathrm{mol} \mathrm{kg}{ }^{-1}\right)$ $\square$ Control

Hemin IP $\left(80 \mu \mathrm{mol} \mathrm{kg}{ }^{-1}\right)$

Hemin neb $\left(2 \mu \mathrm{mol} \mathrm{kg}{ }^{-1}\right)$

Hemin neb $\left(0.4 \mu \mathrm{mol} \mathrm{kg}{ }^{-1}\right)$

$\square$ Control

曰Hemin IP $\left(80 \mu \mathrm{mol} \mathrm{kg}^{-1}\right)$

$\mathbf{\infty}$ Hemin neb $\left(2 \mu \mathrm{mol} \mathrm{kg}{ }^{-1}\right)$

四 Hemin neb $\left(0.4 \mu \mathrm{mol} \mathrm{kg}{ }^{-1}\right)$

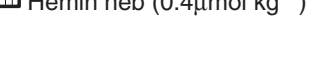


Their definition of the early phase of inflammation included the activation of Toll-like receptor-4, followed by the activation of MyD88 (myeloid differentiation factor 88), leading to the phosphorylation of $\mathrm{NF \kappa B}$ and an increase in the levels of cytokines. The subsequent late phase of inflammation, including PMN influx, was postulated to depend on leukocytic HO-1. Thus, the authors investigated only the early phase of inflammation. Their hypothesis regarding the dependency of the late phase of inflammation on leukocytic HO-1 was based on the findings of Lee and Chau, ${ }^{50}$ who discovered that IL10 administration induced HO-1 expression in vitro in murine macrophages and increased survival in vivo after intraperitoneal LPS administration. In both of their assays, in vitro and in vivo, the TNF $\alpha$ levels were reduced and were interpreted to be crucial for the anti-inflammatory effect of HO-1. We determined the $\mathrm{TNF} \alpha$ levels in the BAL of the wild-type and $\mathrm{HO}-1^{\text {flox/flox }}$ mice subjected to LPS-induced pulmonary inflammation. After HO-1 activation, the TNF $\alpha$ levels were reduced in both strains; therefore, we conclude that leukocytic HO-1 is not necessary for reducing the TNF $\alpha$ levels after HO-1 stimulation. Notably, the overall level of TNF $\alpha$ was significantly higher but the level of the chemokine CXCL1 was significantly lower in the HO- $1^{\text {flox/flox }}$ mice. The chemokine CXCL1 is known to be crucial for neutrophil migration to inflammatory sites, whereas TNF $\alpha$ induces the vascular adhesion molecule-1 and intercellular adhesion molecule-1, promoting neutrophil adhesion to the endothelium. ${ }^{51,52}$ Because our final results of the PMN counts in the BAL equivalent between the two strains, these two conditions with different chemokine levels appear to interfere with one another.

The release of a complex mixture of chemokines is critical for the initiation and perpetuation of the inflammatory response, particularly in the lung, where cells must receive distinct signals to traffic through its various compartments. The observed differences in the release of chemokines between the wild-type and $\mathrm{HO}-1^{\text {flox/flox }}$ mice may suggest a role of myeloid HO- 1 . However, the release of chemokines alone is not sufficient to initiate or-more importantly-maintain cell migration. In our study, nonmyeloid HO-1 appears to be the most critical form of HO-1, as demonstrated by all of our functional experiments.

Hemin has been shown to induce HO-1 in humans ${ }^{53}$ and has already displayed therapeutic potential for the treatment of acute intermittent porphyria. ${ }^{54}$ In this study, we provided evidence that the administration of hemin reduced PMN migration in all three compartments of the lung, decreased the release of chemokines, and enhanced endothelial integrity. In addition, we demonstrated its anti-inflammatory effects when administered after the inflammatory stimulus, emphasizing its clinical potential.

Ryter et al. ${ }^{55}$ reasoned in their review of the role of $\mathrm{HO}-1$ as a therapeutic strategy in critical care medicine that HO-1 induction in experimental studies is typically not suitable for clinical use because of the toxicity of $\mathrm{HO}-1$ activators. In this study, we significantly reduced the required hemin dose using the inhalation administration route, resulting in equivalent anti-inflammatory effects on microvascular permeability.
Topical administration of hemin even enhanced the reduction in the PMN counts in the BAL. Consequently, typical side effects of systemic hemin administration, such as constipation, headaches, nausea, and vomiting, ${ }^{53}$ might be less prominent using the inhalation route.

Zijlstra et al. ${ }^{56}$ used dry powder inhalation of hemin to induce HO- 1 and detected a dose-dependent increase in HO-1 protein expression. ${ }^{14}$ This result confirms our findings of a diminished anti-inflammatory effect of $\mathrm{HO}-1$ at further reduced concentrations. Dry powder inhalation requires a self-breathing individual and is suitable for chronic use, for example, for asthmatic patients. The nebulization of dissolved hemin, as used in this study, is more suitable for and easy to administer to the typically ventilated patients with ALI and acute respiratory distress syndrome. In addition, we showed evidence that topical administration of hemin exerts anti-inflammatory effects on the two main hallmarks of pulmonary inflammation: PMN migration and microvascular permeability.

In conclusion, the anti-inflammatory effects of HO-1 on pulmonary inflammation affect the two primary characteristics of acute lung injury: PMN migration and microvascular permeability. PMN migration to the different compartments of the lung and endothelial cellular integrity, particularly microvascular permeability were mediated by nonmyeloid HO-1. Nebulized hemin administration reduced the required dose by a factor of 40 and effectively stimulated HO-1 after LPS inhalation, emphasizing its clinical potential.

\section{METHODS}

Animals. The HO-1 (HMOX1) $)^{\text {flox/flox }}$ mice were obtained from Alexander Fleming (Biomedical Sciences Research Centre, Varkiza, Greece) and were crossed with B6.129P2-Lyz2 ${ }^{\operatorname{tm} 1(\mathrm{cre}) I f o} / \mathrm{J}$ mice (Charles River Laboratories, Sulzfeld, Germany) to excise the HO-1 gene from the myeloid cell lineage, including monocytes, mature macrophages, and granulocytes. Genotyping of the mice was performed according to the manufacturers' inscription. Corresponding wild-type littermate mice were obtained from Charles River Laboratories. All mice were male and between 8 and 12 weeks of age. There were no phenotypic differences between wild-type and $\mathrm{HO}-1^{\text {flox/flox }}$ mice and they were not affected by the conditional knockout. All animal protocols were approved by the animal care and use committee of the University of Tübingen.

To further confirm the transcriptional suppression of $\mathrm{HO}-1$ at the protein level, we quantified HO-1 protein expression in blood cells via immunofluorescence $(n=4)$. Venous blood was collected from the animals, permeabilized and incubated with the primary antibodies of rabbit anti-HO-1 (Enzo Life Sciences, Lörrach, Germany), and simultaneously with one primary antibody against a leukocyte cell type: goat anti-CD14 for monocytes, goat anti-CD3 and anti-CD19 for lymphocytes (Santa Cruz Biotechnology, Santa Cruz, CA), and rat anti-Ly-6B.2 for PMNs (Bio-Rad AbD Serotec, Puchheim, Germany), all used at a dilution of 1:100. Alexa 488 and Alexa 594 (Invitrogen, Life Technologies, Darmstadt, Germany) were used as secondary antibodies at a dilution of 1:100. The images were visualized using a fluorescence microscope (Axiophot, Carl Zeiss, Heidelberg, Germany) equipped with AxioVision 4.8 software.

In addition, we isolated PMNs from the bone marrow of the wildtype and HO- $1^{\text {flox/flox }}$ mice. The PMNs were separated using a density gradient of Histopaque 1119 and 1083 (Sigma-Aldrich, Steinheim, Germany). Mononuclear cells and PMNs from 10 mice were pooled. 
Some samples served as controls, a portion of which were stimulated with $100 \mathrm{ng} \mathrm{ml}^{-1}$ phorbol myristate acetate (AppliChem, Darmstadt, Germany) for $60 \mathrm{~min}$. Other cells were incubated in hemin $(5 \mu \mathrm{M})$ for $60 \mathrm{~min}$, followed by stimulation with phorbol myristate acetate. Then, RNA was extracted. Reverse transcription was performed on the total RNA samples using a SuperScript III Transcription kit (Invitrogen) and oligo(dT) primers. To measure the transcriptional activity of $\mathrm{HO}$ 1, HO-1 mRNA was quantified via reverse transcriptase-PCR (iCycler; Bio-Rad Laboratories, Hercules, CA) (5'-GAGATTGAGCGCAA CAAGGA- $3^{\prime}$ and $5^{\prime}$-AGCGGTAGAGCTGCTTGAACT- $3^{\prime}$ ). Murine $18 \mathrm{~S}$ expression served as the loading control (primers: $5^{\prime}$-CCATCCA ATCGGTAGTAGCG-3' and 5'-GTAACCCGTTGAACCCCATT- $3^{\prime}$ ).

Blood counts. To exclude discrepancies in the counts of leukocytes between the HO- $1^{\text {flox/flox }}$ and wild-type mice, differential blood counts were performed on peripheral blood (Diff Quik, Dade Behring, Newark, DE) $(n=4)$.

HO-1 stimulation/inhibition. Hemin was purchased from SigmaAldrich, and $\mathrm{SnPP}$ was obtained from Frontier Scientific (Logan, UT). Hemin was injected IP at $80 \mu \mathrm{mol} \mathrm{kg}^{-1} 24 \mathrm{~h}$ before the inflammatory stimulus, ${ }^{57}$ whereas SnPP $\left(50 \mu \mathrm{mol} \mathrm{kg}^{-1}\right)$ was administered IP $1 \mathrm{~h}$ before the stimulus. ${ }^{58}$ In additional experiments, hemin was applied topically via nebulization using a nose-only inhaler (Onares, Westwood, NJ) $(n=8)$.

Murine model of acute lung injury. LPS inhalation was performed $24 \mathrm{~h}$ before the actual experiments. Between 4 and 8 animals inhaled nebulized LPS from Salmonella enteritidis (Sigma-Aldrich) (a total of $7 \mathrm{ml}, 500 \mu \mathrm{g} \mathrm{ml}^{-1}$ ) in a custom-made chamber. LPS inhalation reproducibly led to acute pulmonary inflammation, including the migration of PMNs to different compartments of the lung (the intravascular, interstitial, and alveolar compartments), ${ }^{59}$ increased microvascular permeability, and the chemokine release. Control mice were exposed to saline as an aerosol.

\section{Immunohistochemistry}

$P M N$-specific staining. The animals were pretreated with hemin, and in the case of the inhibition of HO-1, treated with SnPP. At $24 \mathrm{~h}$ after LPS inhalation, the circulatory system of the lungs was flushed $(n=4)$. The lungs were inflated with $4 \%$ paraformaldehyde for $10 \mathrm{~min}$ at $25 \mathrm{cmH}_{2} \mathrm{O}$, removed, and fixed in paraformaldehyde for $24 \mathrm{~h}$. As described previously, ${ }^{60}$ paraffin-embedded sections were stained for PMNs using the avidin-biotin technique (Vector Laboratories, Burlingame, CA) with a specific antibody to neutrophils (clone 7/4; Caltag Laboratories, Burlingame, CA).

HO-1 specific staining. $\mathrm{HO}-1$ was stimulated in the animals as described above $(n=4)$. Immunohistology was performed as described above but using a HO-1 specific antibody (Enzo Life Sciences) $(n=4)$. DAPI (4',6-diamidino-2-phenylindole) was used for nuclear staining, and the endothelium was stained with an antibody against von Willebrand Factor (Santa Cruz Biotechnology). The sections were analyzed by a pathologist who was blinded to the treatment regimen.

In vivo migration assay. To determine $\mathrm{PMN}$ migration to the different compartments of the lung (intravascular, interstitial, alveolar space), a flow cytometry-based method was used as described in detail before. ${ }^{59}$ All intravascular PMNs were labeled via the injection of fluorescent GR-1 (clone RB6-8C5, Lymphocyte Culture, Center Core, Chalottesville, VA) into the tail vein of the mice. To remove nonadherent leukocytes from the pulmonary vasculature, the lungs were perfused to remove the blood. PMNs from the alveolar space were obtained via BAL. The lungs were homogenized and incubated in fluorescent antibodies against CD45 (clone 30-F11, Becton Dickinson, Heidelberg, Germany) and 7/4 (clone 7/4). Intravascular PMNs were then identified in the dot plots as $\mathrm{CD} 45^{+}, 7 / 4^{+}$, and GR-1 ${ }^{+}$, whereas the interstitial
PMNs were identified as CD $45^{+}, 7 / 4^{+}$, and GR1'. The absolute cell counts were determined in the BAL and the lungs $(n \geq 6)$.

Microvascular leakage. To investigate the role of nonmyeloid and myeloid HO-1 in LPS-induced microvascular leakage, Evans blue (20 $\mathrm{mg} \mathrm{kg}^{-1}$; Sigma Aldrich) was injected into the tail vein $6 \mathrm{~h}$ after LPS exposure $(n \geq 5)$, and microvascular permeability was determined in the $\mathrm{HO}-1^{\text {flox/flox }}$ and wild-type animals. At $30 \mathrm{~min}$ after the injection of Evans blue, thoracotomy was performed, intravascular Evans blue was removed from the lungs, and the lungs were homogenized. Evans blue was extracted using formamid overnight, and the Evans blue concentration was determined colorimetrically. ${ }^{61}$

Chemokine release. The release of CXCL1 (keratinocyte-derived chemokine), CXCL2/3 (macrophage inflammatory protein-2), TNF $\alpha$, and IL6 was measured in the BAL of mice $3 \mathrm{~h}$ after LPS inhalation using enzyme-linked immunosorbent assay kits (R\&D Systems, Minneapolis, MN) ( $n \geq 7)$ according to the manufacturer's protocol.

In vitro PMN migration assay. To investigate the impact of CXCL1 and CXCL2/3 on PMN migration after stimulation of HO-1, we performed an in vitro PMN migration assay. Therefore, human pulmonary epithelial cells (H441) were cultivated on inserts of a transwell system $(3.0 \mu \mathrm{m}$ pore size, $6.5 \mathrm{~mm}$ diameter; Costar, Cambridge, MA) until reaching confluence and incubated with $5 \mu \mathrm{M}$ hemin. Human PMNs were isolated by histopaque (Sigma-Aldrich) and migrated through a monolayer of human pulmonary epithelial cells along a chemotactic gradient of either CXCL1 (100 ng ml ${ }^{-1}$; R\&D Systems) or CXCL2/3 (200 $\mathrm{ng} \mathrm{ml}^{-1}$; PeproTech, Hamburg, Germany). Migrated PMNs were quantified by the determination of myeloperoxidase (absorption length: $405 \mathrm{~nm}$ ) in the bottom wells $(n \geq 4)$. For a better comparison between the chemokines, values were normalized in relation to the corresponding control.

In additional experiments, the release of CXCL1 and CXCL2/3 was determined in murine pulmonary epithelial cells (MLE 12, ATCC, Manassas, VA), murine alveolar macrophages (MH-S, ATCC), and freshly isolated PMNs from murine bone marrow (histopaque, SigmaAldrich). Cells were incubated with $5 \mu \mathrm{m}$ hemin for $60 \mathrm{~min}$ and stimulated with LPS $\left(100 \mu \mathrm{g} \mathrm{ml}^{-1}\right)$ for $4 \mathrm{~h}(n \geq 4)$. Chemokine concentrations were analyzed via enzyme-linked immunosorbent assay as described above.

Cytoskeletal remodeling. We investigated the formation of stress fibers to characterize the impact of $\mathrm{HO}-1$ on cytoskeletal remodeling. H441 cells were plated on gelatin-coated glass slides, adhered overnight (medium containing 10\% fetal bovine serum), incubated in hemin (5 $\mu \mathrm{M})$ for $1 \mathrm{~h}$, and then stimulated with LPS $\left(100 \mathrm{ng} \mathrm{ml}^{-1}\right)$ for $15 \mathrm{~min}$. Untreated cells served as controls. The cells were fixed, permeabilized (0.1\% Triton X-100, Sigma, St Louis, MO), and stained for F-actin as previously described. ${ }^{62}$ Coverslips were mounted on glass slides, and microscopy was performed using a confocal fluorescence microscope (LSM 510, Zeiss, Goettingen, Germany). The images are representative of four experiments that produced similar results.

Oxidative burst. We evaluated the effect of HO-1 stimulation on the release of oxidative products from PMNs and mononuclear cells of the wild-type and HO-1 ${ }^{\text {flox/flox }}$ mice. Cells were isolated from the bone marrow, and PMNs were labeled with GR-1 and 7/4 as described above. Macrophages and monocytes were labeled with Ly-6C (clone HK1.4; BioLegend, San Diego, CA). All samples were stained with $5 \mu \mathrm{g}$ dihydroethidium (Sigma-Aldrich) and stimulated with $100 \mathrm{ng} \mathrm{ml}^{-}$ phorbol myristate acetate (AppliChem) for $30 \mathrm{~min}$. PMNs were stained with GR-1 and 7/4 as described above. The respective mean fluorescence intensity of dihydroethidium was measured $(n=6)$. Dihydroethidium oxidizes to ethidium bromide when it reacts with oxidative species within PMNs. ${ }^{63}$

Western blot. In the wild-type and $\mathrm{HO}-1^{\text {flox/flox }}$ mice, HO-1 was stimulated, and aerosolized LPS was administered. After $6 \mathrm{~h}$, the lungs 
were removed and prepared for western blot $(n=4)$. The membranes were probed with a rabbit polyclonal anti-NFKB p65 (1:200) (SC-372) or rabbit polyclonal anti-NFkB p52 (1:200, SC-298; Santa Cruz Biotechnology) antibody for NFkB analysis. For analyzing tight junction formation, rabbit polyclonal anti-ZO1 $\left(1 \mu \mathrm{g} \mathrm{ml}^{-1}\right.$; Zymed Laboratories, Thermo Fischer Scientific) and mouse monoclonal antioccludin $\left(0.5 \mu \mathrm{g} \mathrm{ml}^{-1}\right.$; Zymed Laboratories, Thermo Fischer Scientific, Darmstadt, Germany) were used. A rabbit anti-GAPDH antibody was used for the detection of glyceraldehyde 3-phosphate dehydrogenase (GAPDH; Santa Cruz).

HO-1 activity. At $24 \mathrm{~h}$ after LPS exposure, the lungs of the mice were removed to measure the enzymatic activity of HO-1 $(n \geq 4)$. The mice were pretreated with hemin or SnPP, the lungs were weighed, $\mathrm{HO}$ activity buffer was added (twice of weight), and the sample was rapidly frozen in liquid nitrogen. Then, the lungs were homogenized, sonicated, and centrifuged at $18,000 \mathrm{~g}$ for $15 \mathrm{~min}$. The supernatant was used for protein and activity measurements. The cytosol was obtained from the livers of mice that were fasted for $12 \mathrm{~h}$ via centrifugation at $105,000 \mathrm{~g}$ for $27 \mathrm{~min}$. The HO- 1 activity assay consisted of $100 \mu \mathrm{l}$ of supernatant, $131 \mu \mathrm{l}$ of $\mathrm{HO}$ activity buffer, $100 \mu \mathrm{l}$ of liver cytosol, $50 \mu \mathrm{l}$ of glucose-6-phosphate ( $20 \mathrm{~mm}), 4 \mu \mathrm{l}$ of glucose-6-phosphate dehy-

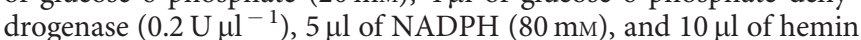
$(1 \mathrm{~mm})$. The probes were incubated for $1 \mathrm{~h}$ in the dark at $37^{\circ} \mathrm{C}$. Then, $500 \mu \mathrm{l}$ of chloroform was added, followed by centrifugation at $15,000 \mathrm{~g}$ for $5 \mathrm{~min}$. Extinction was measured at 464 and $530 \mathrm{~nm}$, and $\mathrm{HO}$ activity was calculated based on protein level that was determined by a colorimetric method (bicinchoninic acid; Thermo Scientific, Rockford, IL).

Statistical analysis. The data are presented as the mean \pm s.d. unless indicated otherwise. Statistical analysis was performed using GraphPad Prism version 5.3 for Windows (GraphPad Software, San Diego, CA). Differences between the groups were evaluated via oneway analysis of variance followed by the Bonferroni post hoc test. An unpaired $t$-test was performed for experiments containing only two groups. $P<0.05$ was considered to be significant.

SUPPLEMENTARY MATERIAL is linked to the online version of the paper at http://www.nature.com/mi

\section{ACKNOWLEDGMENTS}

This work was supported by German Research Foundation grant RE 1683/ 4-1 (to J. Reutershan).

\section{DISCLOSURE}

The authors declared no conflict of interest.

c 2016 Society for Mucosal Immunology

\section{REFERENCES}

1. Esteban, A. et al. Evolution of mechanical ventilation in response to clinical research. Am. J. Respir. Crit. Care Med. 177, 170-177 (2008).

2. Mantovani, A., Cassatella, M.A., Costantini, C. \& Jaillon, S. Neutrophils in the activation and regulation of innate and adaptive immunity. Nat. Rev. Immunol. 11, 519-531 (2011).

3. Farmer, D.G. et al. Disruption of P-selectin signaling modulates cell trafficking and results in improved outcomes after mouse warm intestinal ischemia and reperfusion injury. Transplantation 80, 828-835 (2005).

4. Kolaczkowska, E. \& Kubes, P. Neutrophil recruitment and function in health and inflammation. Nat. Rev. Immunol. 13, 159-175 (2013).

5. Tenhunen, R., Marver, H.S. \& Schmid, R. The enzymatic conversion of heme to bilirubin by microsomal heme oxygenase. Proc. Natl. Acad. Sci. USA 61, 748-755 (1968).

6. Zolak, J.S. et al. Pleural mesothelial cell differentiation and invasion in fibrogenic lung injury. Am. J. Pathol. 182, 1239-1247 (2013).
7. Chen, T.M. et al. Effects of heme oxygenase-1 upregulation on blood pressure and cardiac function in an animal model of hypertensive myocardial infarction. Int. J. Mol. Sci. 14, 2684-2706 (2013).

8. Yi, X., Zhang, G. \& Yuan, J. Renoprotective role of fenoldopam pretreatment through hypoxia-inducible factor-1alpha and heme oxygenase-1 expressions in rat kidney transplantation. Transplant. Proc. 45, 517-522 (2013).

9. Hayashi, S. et al. Characterization of rat heme oxygenase-3 gene. Implication of processed pseudogenes derived from heme oxygenase2 gene. Gene 336, 241-250 (2004).

10. Ryter, S.W. \& Choi, A.M. Heme oxygenase-1/carbon monoxide: from metabolism to molecular therapy. Am. J. Respir. Cell Mol. Biol. 41, 251-260 (2009).

11. Chiang, N. et al. Inhaled carbon monoxide accelerates resolution of inflammation via unique proresolving mediator-heme oxygenase-1 circuits. J. Immunol. 190, 6378-6388 (2013).

12. Park, Y.Y. Ischemia/reperfusion lung injury increases serum ferritin and heme oxygenase-1 in rats. Korean J. Physiol. Pharmacol. 13, 181-187 (2009).

13. Shokawa, T. et al. Induction of heme oxygenase-1 inhibits monocyte chemoattractant protein-1 mRNA expression in U937 cells. J. Pharmacol. Sci. 100, 162-166 (2006).

14. Zijlstra, G.S. et al. Dry powder inhalation of hemin to induce heme oxygenase expression in the lung. Eur. J. Pharm. Biopharm. 67, 667-675 (2007).

15. Raval, C.M. \& Lee, P.J. Heme oxygenase-1 in lung disease. Curr. Drug Targets 11, 1532-1540 (2010).

16. Kawamura, T. et al. Hydrogen gas reduces hyperoxic lung injury via the Nrf2 pathway in vivo. Am. J. Physiol. Lung Cell Mol. Physiol 304, 646-656 (2013).

17. Gong, X., Zhang, L., Jiang, R., Ye, M., Yin, X. \& Wan, J. Anti-inflammatory effects of mangiferin on sepsis-induced lung injury in mice via up-regulation of heme oxygenase-1. J. Nutr. Biochem. 24, 1173-1181 (2012).

18. Hsu, J.T.etal. Role of Akt/HO-1 pathway in estrogen-mediated attenuation of trauma-hemorrhage-induced lung injury. J. Surg. Res. 182, 319-325 (2012).

19. An, L., Liu, C.T., Qin, X.B., Liu, Q.H., Liu, Y. \& Yu, S.Y. Protective effects of hemin in an experimental model of ventilator-induced lung injury. Eur. J. Pharmacol. 661, 102-108 (2011).

20. Brouard, S. et al. Carbon monoxide generated by heme oxygenase 1 suppresses endothelial cell apoptosis. J. Exp. Med. 192, 1015-1026 (2000).

21. Christou, $H$. et al. Prevention of hypoxia-induced pulmonary hypertension by enhancement of endogenous heme oxygenase- 1 in the rat. Circ. Res. 86, 1224-1229 (2000).

22. El-Bassossy, H.M., El-Maraghy, N.N., El-Fayoumi, H.M. \& Watson, M.L. Haem oxygenase-1 induction protects against tumour necrosis factor alpha impairment of endothelial-dependent relaxation in rat isolated pulmonary artery. Br. J. Pharmacol. 158, 1527-1535 (2009).

23. Ayyagari, V.N., Januszkiewicz, A. \& Nath, J. Effects of nitrogen dioxide on the expression of intercellular adhesion molecule-1, neutrophil adhesion, and cytotoxicity: studies in human bronchial epithelial cells. Inhal. Toxicol. 19, 181-194 (2007).

24. Donnelly, L.E. \& Barnes, P.J. Expression of heme oxygenase in human airway epithelial cells. Am. J. Respir. Cell Mol Biol. 24, 295-303 (2001).

25. Sheikh, S.Z. et al. An anti-inflammatory role for carbon monoxide and heme oxygenase-1 in chronic Th2-mediated murine colitis. J. Immunol. 186, 5506-5513 (2011).

26. Lewkowicz, N., Klink, M., Mycko, M.P. \& Lewkowicz, P. NeutrophilCD4 + CD25 + Tregulatory cell interactions: a possible new mechanism of infectious tolerance. Immunobiology 218, 455-464 (2013).

27. Schmal, H., Shanley, T.P., Jones, M.L., Friedl, H.P. \& Ward, P.A. Role for macrophage inflammatory protein-2 in lipopolysaccharide-induced lung injury in rats. J. Immunol. 156, 1963-1972 (1996).

28. Schumacher, C., Clark-Lewis, I., Baggiolini, M. \& Moser, B. High- and lowaffinity binding of GRO alpha and neutrophil-activating peptide 2 to interleukin 8 receptors on human neutrophils. Proc. Natl. Acad. Sci. USA 89, 10542-10546 (1992).

29. Becker, S., Quay, J., Koren, H.S. \& Haskill, J.S. Constitutive and stimulated MCP-1, GRO alpha, beta, and gamma expression in human airway 
epithelium and bronchoalveolar macrophages. Am. J. Physiol. 266, L278-L286 (1994).

30. Walther, M. et al. HMOX1 gene promoter alleles and high $\mathrm{HO}-1$ levels are associated with severe malaria in Gambian children. PLoS Pathog. 8, 1002579 (2012).

31. De, S.F., Totaro, M.G., Prosperini, E., Notarbartolo, S., Testa, G. \& Natoli, G. The histone H3 lysine-27 demethylase Jmjd3 links inflammation to inhibition of polycomb-mediated gene silencing. Cell $\mathbf{1 3 0}$, 1083-1094 (2007).

32. Anderson, J.M., Stevenson, B.R., Jesaitis, L.A., Goodenough, D.A. \& Mooseker, M.S. Characterization of ZO-1, a protein component of the tight junction from mouse liver and Madin-Darby canine kidney cells. J. Cell. Biol. 106, 1141-1149 (1988).

33. Itoh, M., Nagafuchi, A., Yonemura, S., Kitani-Yasuda, T., Tsukita, S. \& Tsukita, S. The 220-kD protein colocalizing with cadherins in non-epithelial cells is identical to ZO-1, a tight junction-associated protein in epithelial cells: cDNA cloning and immunoelectron microscopy. J. Cell. Biol. 121, 491-502 (1993).

34. Stevenson, B.R., Siliciano, J.D., Mooseker, M.S. \& Goodenough, D.A. Identification of ZO-1: a high molecular weight polypeptide associated with the tight junction (zonula occludens) in a variety of epithelia. J. Cell. Biol. 103, 755-766 (1986).

35. Gruenheid, S. \& Finlay, B.B. Microbial pathogenesis and cytoskeletal function. Nature 422, 775-781 (2003).

36. Chen, C., Zhang, F., Zhang, Z., Peng, M., Wang, Y. \& Chen, Y. TLR4 signaling-induced heme oxygenase upregulation in the acute lung injury: role in hemorrhagic shock and two-hit induced lung inflammation. Mol. Biol. Rep. 40, 1167-1172 (2013).

37. Kawashima, A., Oda, Y., Yachie, A., Koizumi, S. \& Nakanishi, I. Heme oxygenase-1 deficiency: the first autopsy case. Hum. Pathol. 33, 125-130 (2002).

38. Yachie, A. et al. Oxidative stress causes enhanced endothelial cell injury in human heme oxygenase-1 deficiency. J. Clin. Invest. 103, 129-135 (1999).

39. Poss, K.D. \& Tonegawa, S. Reduced stress defense in heme oxygenase 1-deficient cells. Proc. Natl. Acad. Sci. USA 94, 10925-10930 (1997).

40. Poss, K.D. \& Tonegawa, S. Heme oxygenase 1 is required for mammalian iron reutilization. Proc. Natl. Acad. Sci. USA 94, 10919-10924 (1997).

41. Zenclussen, M.L., Jensen, F., Rebelo, S., El-Mousleh, T., Casalis, P.A. \& Zenclussen, A.C. Heme oxygenase-1 expression in the ovary dictates a proper oocyte ovulation, fertilization, and corpora lutea maintenance. Am. J. Reprod. Immunol. 67, 376-382 (2012).

42. Ishikawa, K., Navab, M. \& Lusis, A.J. Vasculitis, atherosclerosis, and altered HDL composition in heme-oxygenase-1-knockout mice. Int. J. Hypertens. 2012, 948203 (2012).

43. Starzynski, R.R. et al. Ferroportin expression in haem oxygenase 1-deficient mice. Biochem. J. 449, 69-78 (2013).

44. Tzima, S., Victoratos, P., Kranidioti, K., Alexiou, M. \& Kollias, G. Myeloid heme oxygenase- 1 regulates innate immunity and autoimmunity by modulating IFN-beta production. J. Exp. Med. 206, 1167-1179 (2009).

45. Li, Q.F., Zhu, Y.S., Jiang, H., Xu, H. \& Sun, Y. Heme oxygenase-1 mediates the anti-inflammatory effect of isoflurane preconditioning in LPS-stimulated macrophages. Acta Pharmacol. Sin. 30, 228-234 (2009).
46. Otterbein, L.E. et al. Carbon monoxide has anti-inflammatory effects involving the mitogen-activated protein kinase pathway. Nat. Med. 6 , 422-428 (2000).

47. Liu, Z. et al. Protective effect of gossypol on lipopolysaccharide-induced acute lung injury in mice. Inflamm. Res. 62, 499-506 (2013).

48. Fan, X.F. et al. The Apelin-APJ axis is an endogenous counter-injury mechanism in experimental acute lung injury. Chest 147, 969-978 (2014).

49. Tsao, C.M. et al. Levosimendan attenuates multiple organ injury and improves survival in peritonitis-induced septic shock: studies in a rat model. Crit. Care 18, 652 (2014).

50. Lee, T.S. \& Chau, L.Y. Heme oxygenase- 1 mediates the anti-inflammatory effect of interleukin-10 in mice. Nat. Med. 8, 240-246 (2002).

51. Zhang, J. et al. Regulation of endothelial cell adhesion molecule expression by mast cells, macrophages, and neutrophils. PLoS One 6, e14525 (2011).

52. Wengner, A.M., Pitchford, S.C., Furze, R.C. \& Rankin, S.M. The coordinated action of G-CSF and ELR + CXC chemokines in neutrophil mobilization during acute inflammation. Blood 111, 42-49 (2008).

53. Bharucha, A.E. et al. First-in-human study demonstrating pharmacological activation of heme oxygenase-1 in humans. Clin. Pharmacol. Ther. 87, 187-190 (2010).

54. Siegert, S.W. \& Holt, R.J. Physicochemical properties, pharmacokinetics, and pharmacodynamics of intravenous hematin: a literature review. Adv. Ther. 25, 842-857 (2008).

55. Ryter, S.W. \& Choi, A.M. Heme oxygenase-1/carbon monoxide: novel therapeutic strategies in critical care medicine. Curr. Drug Targets 11, 1485-1494 (2010).

56. De Boer, A.H., Hagedoorn, P., Westerman, E.M., Le Brun, P.P., Heijerman, H.G. \& Frijlink, H.W. Design and in vitro performance testing of multiple air classifier technology in a new disposable inhaler concept (Twincer) for high powder doses. Eur. J. Pharm. Sci. 28, 171-178 (2006).

57. Zhan, L.Y., Xia, Z.Y., Chen, C. \& Wang, X.Y. Effect of Radix Paeoniae Rubra on the expression of $\mathrm{HO}-1$ and $\mathrm{NOS}$ in rats with endotoxin-induced acute lung injury. Chin. J. Traumatol. 9, 181-186 (2006).

58. Taylor, J.L., Carraway, M.S. \& Piantadosi, C.A. Lung-specific induction of heme oxygenase-1 and hyperoxic lung injury. Am. J. Physiol. 274, L582-L590 (1998).

59. Reutershan, J., Basit, A., Galkina, E.V. \& Ley, K. Sequential recruitment of neutrophils into lung and bronchoalveolar lavage fluid in LPS-induced acute lung injury. Am. J. Physiol. Lung Cell Mol. Physiol. 289, 807-815 (2005).

60. Konrad, F.M., Witte, E., Vollmer, I., Stark, S. \& Reutershan, J. Adenosine receptor A2b on hematopoietic cells mediates LPS-induced migration of PMNs into the lung interstitium. Am. J. Physiol. Lung Cell Mol. Physiol. 303, 425-438 (2012).

61. Wang, I.F. et al. Role of inducible nitric oxide synthase in pulmonary microvascular protein leak in murine sepsis. Am. J. Respir. Crit. Care Med. 165, 1634-1639 (2002).

62. Reutershan, J. et al. Critical role of endothelial CXCR2 in LPS-induced neutrophil migration into the lung. J. Clin. Invest. 116, 695-702 (2006).

63. Kragsbjerg, P., Jurstrand, M. \& Fredlund, H. Similar inflammatory response in human whole blood to live Streptococcus pneumoniae of different serotypes. Clin. Microbiol. Infect. 10, 174-177 (2004). 